\title{
An introduction of Markov chain Monte Carlo method to geochemical inverse problems: Reading melting parameters from REE abundances in abyssal peridotites
}

Boda Liu and Yan Liang*

\begin{abstract}
Markov chain Monte Carlo (MCMC) simulation is a powerful statistical method in solving inverse problems that arise from a wide range of applications. In Earth sciences applications of MCMC simulations are primarily in the field of geophysics. The purpose of this study is to introduce MCMC methods to geochemical inverse problems related to trace element fractionation during mantle melting. MCMC methods have several advantages over least squares methods in deciphering melting processes from trace element abundances in basalts and mantle rocks. Here we use an MCMC method to invert for extent of melting, fraction of melt present during melting, and extent of chemical disequilibrium between the melt and residual solid from REE abundances in clinopyroxene in abyssal peridotites from Mid-Atlantic Ridge, Central Indian Ridge, Southwest Indian Ridge, Lena Trough, and American-Antarctic Ridge. We consider two melting models: one with exact analytical solution and the other without. We solve the latter numerically in a chain of melting models according to the Metropolis-Hastings algorithm. The probability distribution of inverted melting parameters depends on assumptions of the physical model, knowledge of mantle source composition, and constraints from the REE data. Results from MCMC inversion are consistent with and provide more reliable uncertainty estimates than results based on nonlinear least squares inversion. We show that chemical disequilibrium is likely to play an important role in fractionating LREE in residual peridotites during partial melting beneath mid-ocean ridge spreading centers. MCMC simulation is well suited for more complicated but physically more realistic melting problems that do not have analytical solutions.
\end{abstract}




\section{Introduction}

31 The abundance and distribution of trace elements in primitive basalts and residual peridotites

32 are important to understanding mantle source compositions and mantle melting processes.

33 During partial melting, abundances of trace elements in interstitial melt and residual solid are

34 redistributed or fractionated in accordance with their solid-melt partition coefficients, extent of

35 melting, and style of melt extraction. Interpretations of trace element data, therefore, depend

36 critically on melting models, melting parameters, and mantle source composition. Simple

37 melting models that have frequently been used in the interpretation of trace element data in

38 basalts and residual peridotites include batch melting, incremental batch melting, fractional

39 melting, and dynamic melting models (e.g., Albarède, 1995; Shaw, 2006; Zou, 2007). A

40 common feature of these simple melting models is that they all have explicit analytical solutions

41 relating melt and residual solid compositions to the degree of melting experienced by the solid.

42 In more complicated but physically more realistic melting models, such as double porosity

43 melting models and disequilibrium melting models (Qin, 1992; Iwamori, 1993b, 1994;

44 Lundstrom, 2000; Ozawa, 2001; Jull et al., 2002; Van Orman et al., 2002; Liang and Parmentier,

45 2010; Liang and Peng, 2010), there are no analytical solutions to the mass conservation

46 equations governing the fractionation of a trace element in the partial melt and residual solid,

47 except a few special cases. Numerical methods are used to solve the governing equations

48 (Richter, 1986; Jull et al., 2002; Spiegelman and Kelemen, 2003).

49 Interpretations of basalt and peridotite trace element data typically follow one of two 50 approaches or methods (Allegre and Minster, 1978): forward method and inverse method. In the

51 forward approach, one calculates trace element abundances in the melt and residual solid or

52 mineral (often clinopyroxene) for a range of melting parameters (e.g., 0-20\% melting, 0-2\% 
53 trapped melt in the dynamic melting model) using several melting models for a group of trace

54 elements in question (e.g., REE and HFSE). Results from the forward calculation are then

55 compared with measured trace element data on a spider diagram, element vs. element diagrams

56 (e.g., Ti vs. $\mathrm{Zr}$ ), element vs. element ratio diagrams (e.g., $\mathrm{Sm} / \mathrm{Yb}$ vs. $\mathrm{Yb}$ ), or element ratio vs.

57 element ratio diagrams (e.g., Ti/Zr vs. $\mathrm{Sm} / \mathrm{Yb}$ ). The model is deemed acceptable or successful if

58 part or all of the observed trace element data in samples included in the study can be explained or

59 bracketed by those predicted by the forward model calculations. If the melting model fails to

60 explain part of the observed data (e.g., LREE enrichment in residual clinopyroxene), additional

61 processes such as late-stage melt impregnation or mantle metasomatism are invoked and further

62 tested. Such forward modeling followed by direct comparison with measured data has been

63 widely used in the interpretation of trace element data from primitive basalts and residual

64 peridotites (e.g., Langmuir et al., 1977, 2006; McKenzie, 1985; Johnson et al., 1990; Kelemen et

65 al., 1997; Niu and Hékinian, 1997; Shimizu, 1998; Lundstrom, 2000; Hellebrand et al., 2002;

66 Jull et al., 2002; Van Orman et al., 2002; Spiegelman and Kelemen, 2003; Niu, 2004; Kelley et

67 al., 2006; Liang and Parmentier, 2010; Brunelli et al., 2006, 2014).

68 In the inverse approach, the melting parameters are extracted from measured trace element

69 data through least squares analysis (Allegre and Minster, 1978; Minster and Allegre, 1978;

70 Hofmann and Feigenson, 1983; McKenzie and O'Nions, 1991; Albarède, 1995; Zou, 2007). Here

71 one minimizes a Chi-square defined by the measured trace element concentrations and those

72 predicted by the melting model and weighted by data quality. Early applications of the inverse

73 method to mantle melting follow the strategies outlined in Minster and Allegre (1978) and

74 Hofmann and Feigenson (1983). Given the relatively poor knowledge of mineral-melt partition

75 coefficients, melting reaction, and mantle composition and mineralogy at the time, these early 
76 studies used the batch melting model and incompatible trace element ratios and abundances in

77 basalts to invert for bulk solid-melt partition coefficients and mantle mineralogy (Feigenson et al.,

78 1983; Hofmann and Feigenson, 1983; Ormerod et al., 1991; Feigenson and Carr, 1993).

79 McKenzie and coworkers (McKenzie and O'Nions, 1991; Watson and McKenzie, 1991; White et

80 al., 1992; Watson, 1993; Tainton and McKenzie, 1994; McKenzie and O'Nions, 1995; McKenzie

81 and O'Nions, 1998; McKenzie et al., 2004) applied Backus and Gilbert (1968)'s optimization

82 technique (for a summary see Parker, 1977) to invert melt fraction and distribution in a melting

83 column from REE abundances in basalts. In a more restricted case in which the melting model

84 has explicit analytical expression, the nonlinear least squares method (also called the linearized

85 least squares method, abbreviated as "LS" hereafter, Tarantola, 2005) is very useful in inverting

86 all model parameters simultaneously. There are only a few mantle melting studies that took the

87 nonlinear least squares approach. Liang and Peng (2010) used the nonlinear least squares method

88 and a steady-state double porosity model to invert the degree of melting and the extent of melt

89 extraction from REE and $\mathrm{Y}$ abundances in residual clinopyroxene from the Central Indian Ridge

90 (data reported by Hellebrand et al., 2002). LREE abundances in half of the sample set are too

91 high to be consistent with the steady-state model. Liang and Liu (2016) further examined this

92 problem using a disequilibrium perfect fractional melting model. They showed that a small

93 extent of chemical disequilibrium, due to slow diffusion of LREE in clinopyroxene, can explain

94 the elevated LREE abundances in residual clinopyroxenes in the abyssal peridotites. They also

95 noted a positive correlation between the degree of melting and the extent of chemical

96 disequilibrium and attributed it to an increase in melting rate and a decrease in REE diffusion

97 rate along the melting path. However, given the highly nonlinear nature of the melting problem

98 and the simplified melting model used, it is not clear if this is a robust observation for 
99 decompressional melting along a melting column when additional melting parameters are

100 considered. For example, in a more general case of dynamic melting, a small fraction of melt is

101 retained in the melting column, which may affect the interpretation of other melting parameters

102 through nonlinear trade-offs among the melting parameters. Although it is straightforward to

103 develop a disequilibrium dynamic melting model by relaxing model assumptions, the governing

104 mass conservation equations are nonlinear and do not have explicit analytical solutions (e.g.,

105 Liang, 2003), which limits application of the nonlinear least squares inversion method. If more

106 complicated melting models are used to interpret trace element data, robust inversion methods

107 are needed.

108 The purpose of this study is twofold: (1) to introduce Markov chain Monte Carlo (MCMC)

109 methods to geochemical inverse problems related to trace element fractionation during mantle

110 melting, and (2) to further test the robustness of the positive correlation between the degree of

111 melting and the extent of chemical disequilibrium noted earlier. Conservation equations for trace

112 element fractionation during concurrent melting, melt migration and melt-rock interaction

113 generally do not have analytical solutions and hence cannot be easily solved using least squares

114 inversion methods. MCMC methods are a class of powerful statistical tools for solving inverse

115 problems that arise from a wide range of applications, such as physics, chemistry, computational

116 biology, computer science, financial engineering, among others (Robert and Casella, 2004; Liu,

117 2008). In Earth sciences, applications of MCMC methods are primarily in the field of geophysics

118 (Sambridge and Mosegaard, 2002). MCMC methods have several advantages over the least

119 squares methods in inverting melting parameters from trace element abundances in basalts and

120 mantle rocks. First, MCMC methods can handle any model or equation that has no explicit

121 analytical solution. Second, MCMC methods can take advantage of prior knowledge of the 
122 system in question (e.g., based on previous studies, we know mantle melting is near fractional)

123 and further improve the estimation of model parameters based on new observations in hand, an

124 important feature that nonlinear least squares inversion methods do not have. Third, MCMC

125 algorithms can handle multiple local minima in nonlinear inverse problems that may pose a 126 challenge to nonlinear least squares analysis. Finally, MCMC simulations can provide insights 127 into uncertainties of model parameters with nonlinear trade-off.

128 The remaining part of this paper is organized as follows. In Section 2, we outline the 129 procedure of a widely used MCMC method that is based on the Metropolis-Hastings algorithm. 130 In Section 3, we use two melting models and abyssal peridotite data from Central Indian Ridge 131 to highlight the advantages of the MCMC method: a disequilibrium fractional melting model that 132 has an explicit analytical solution, and a more general model of disequilibrium dynamic melting 133 that has no analytical solution. In Sections 4 and 5, we use the MCMC method and the 134 disequilibrium dynamic melting model to invert melting parameters from REE and Y 135 abundances in clinopyroxene in abyssal peridotites from four additional ridge systems: Mid136 Atlantic Ridge, Southwest Indian Ridge, Lena Trough, and American-Antarctic Ridge. We show 137 that a robust positive correlation between the degree of melting and the extent of disequilibrium 138 for REE in clinopyroxene exists in abyssal peridotites from Southwest Indian Ridge and Central 139 Indian Ridge and discuss our results in the context of adiabatic mantle melting. Finally in Section 1406 , we outline potential applications of MCMC methods to more general cases of mantle melting. 
143 Markov chain Monte Carlo method was first introduced by Metropolis et al. (1953) to study

144 macroscopic equilibrium of interacting molecules in statistical mechanics. The Metropolis

145 algorithm was extended by Hastings (1970) for more general cases. The MCMC method uses the

146 posterior distribution to estimate the probability of model parameters given data as constraints.

147 Here posterior distribution is the distribution of unknown model parameters based on the

148 observed data. By randomly generating trial models and accepting or rejecting the trial model in

149 accordance with a transition probability, the Metropolis-Hastings algorithm produces a chain of

150 models whose distribution converges to posterior distribution, i.e., the desired parameters that

151 reproduce the observed data.

152 2.1. The estimate of model parameters: Posterior distribution

153 To estimate a model parameter is to determine the probability distribution of the model

154 parameter (i.e., their best-estimated values and associate uncertainties) given data as constraints.

155 For example, REE abundances in an abyssal peridotite may suggest that $10 \%$ melting is more

156 likely to explain the observed REE data than 5\% melting. In other words, the degree of melting

$157(F)$ has a higher probability at $10 \%$ than at $5 \%$. There exists a posterior distribution that specifies

158 the probability of $F$ within a range of values. There are two ways to describe posterior

159 distribution: (1) a probability density function characterized by a finite number of parameters,

160 and (2) a sample set consisting of a large number of model parameters belonging to the posterior

161 distribution. The nonlinear least squares method utilizes the former with a normal distribution

162 (characterized by two parameters: the mean and the standard deviation), whereas MCMC

163 methods resort to the latter which is more general. The mean and standard deviation of the

164 sample of model parameters acquired by MCMC methods are consistent with the nonlinear least

165 squares method if the posterior distribution is a normal distribution. 
Let $\mathbf{m}$ be a vector of model parameters. For the case of disequilibrium fractional melting 167 model used in Section 3.2, $\mathbf{m}=(F, \varepsilon)$, where $\varepsilon$ is a measure of chemical disequilibrium defined 168 in the next section. Let $\mathbf{C}$ be the data or concentration vector with each component $C_{\mathrm{i}}$ as the 169 concentration of element $i$. In Bayesian statistics, the posterior probability of a model, $p(\mathbf{m} \mid \mathbf{C})$, is 170 proportional to the product of the data-independent prior probability of this model, $\theta(\mathbf{m})$, and

171 the likelihood of the model in observing the data, L(C|m) (Grandis et al., 1999; Sambridge and 172 Mosegaard, 2002; Robert and Casella, 2004; Tarantola, 2005; Korenaga and Karato, 2008), viz., $p(\mathbf{m} \mid \mathbf{C})=A \cdot L(\mathbf{C} \mid \mathbf{m}) \cdot \theta(\mathbf{m})$,

$\int_{\mathbf{m}} p(\mathbf{m} \mid \mathbf{C}) d \mathbf{m}=1$,

173 where the bold letters are vectors; $\mathrm{A}$ is a constant which forces $p(\mathbf{m} \mid \mathbf{C})$ to satisfy Eq. 2. (Since we 174 will only use ratios of $p(\mathbf{m} \mid \mathbf{C})$ in MCMC simulations, the constant A will be set as 1.) In terms of 175 notation, the vertical bar "|" stands for a conditional probability. For example, $p(\mathbf{m} \mid \mathbf{C})$ reads the 176 probability of $\mathbf{m}$ given the observation C. (Symbols used in this study are listed in Table 1.) Eq. 1772 is the cumulative probability condition where the integral of the probability of $\mathbf{m}$ given the 178 observation $\mathbf{C}$ over all $\mathbf{m}$ must be one. The prior distribution of model $\theta(\mathbf{m})$ reflects the 179 understanding of the model before analyzing the data. In the simple cases considered in the next 180 section where only the bounds of each model parameter are known, the prior probability $\theta(\mathbf{m})$ is 181 constant within a model space restricted by those bounds, we set $\theta(\mathbf{m})=1$. The likelihood of 182 observing $\mathbf{C}$ given model parameter $\mathbf{m}$ is a function of the misfit or Chi-squares, $\chi^{2}(\mathbf{C}, \mathbf{m})$,

$L(\mathbf{d} \mid \mathbf{m})=\exp \left(-\frac{\chi^{2}(\mathbf{C}, \mathbf{m})}{2}\right)$, 
$\chi^{2}(\mathbf{C}, \mathbf{m})=\sum_{\mathrm{i}}\left(\frac{\log \left(C_{\mathrm{i}}^{\text {predict }}(\mathbf{m})\right)-\log \left(C_{\mathrm{i}}\right)}{\sqrt{\left(\frac{\delta C_{\mathrm{i}}^{0}}{C_{\mathrm{i}}^{0}}\right)^{2}+\left(\frac{\delta C_{\mathrm{i}}}{C_{\mathrm{i}}}\right)^{2}}}\right)^{2}$

183 where $C_{\mathrm{i}}^{\text {predict }}(\mathbf{m})$ is the concentration of element i predicted by model parameter $\mathbf{m}$ (e.g., we

184 can calculate $C_{\mathrm{i}}^{\text {predict }}(\mathbf{m})$ as the prediction of disequilibrium fractional melting model using Eq.

1856 or a more general model such as Eqs. 9-11 below); $C_{\mathrm{i}}^{0}$ is the concentration of element $\mathrm{i}$ in the

186 mantle source; $\delta C_{\mathrm{i}}^{0}$ is the variation in the concentration of element $\mathrm{i}$ in the mantle source; $\delta C_{\mathrm{i}}$ is

187 the uncertainty in the measured concentration of element i. Here for purpose of demonstration,

188 we assume that the relative source variation $\delta C_{\mathrm{i}}^{0} / C_{\mathrm{i}}^{0}$ dominates the relative uncertainty of

189 measurement $\delta C_{\mathrm{i}} / C_{\mathrm{i}}$. The posterior probability is greater if the Chi-square is smaller, i.e. the

190 model fitting the data with smaller overall residue is more probable.

191 2.2. Implementation of MCMC through the Metropolis-Hastings algorithm

192 To obtain the posterior distribution defined by Eqs. 1-4, we carry out MCMC simulations

193 using the Metropolis-Hastings algorithm that consists of the following steps (Hastings, 1970;

194 Sambridge and Mosegaard, 2002; Robert and Casella, 2004; Liu, 2008):

195 Step 1. Start from any model $\mathbf{m}_{\mathbf{0}}$. Calculate predicted observation $\mathbf{C}^{\text {predict }}\left(\mathbf{m}_{\mathbf{0}}\right)$. Calculate the likelihood function $L\left(\mathbf{m}_{\mathbf{0}} \mid \mathbf{C}\right)$ according to Eqs. 3 and 4.

197 Step 2. Suppose $\mathbf{m}_{\mathbf{k}}$ is the current model (if this step follows Step 1, $\mathrm{k}=0$ ). Choose a temporary model $\mathbf{m}_{\text {temp }}$ randomly. Calculate predicted observation $\mathbf{C}^{\text {predict }}\left(\mathbf{m}_{\text {temp }}\right)$. Calculate the likelihood function $L\left(\mathbf{m}_{\text {temp }} \mid \mathbf{C}\right)$ according to Eqs. 3 and 4.

- if the ratio $p\left(\mathbf{m}_{\text {temp }} \mid \mathbf{C}\right) / p\left(\mathbf{m}_{\mathbf{k}} \mid \mathbf{C}\right)>1$, accept $\mathbf{m}_{\text {temp }}$ as $\mathbf{m}_{\mathbf{k}+\mathbf{1}}$. 
- else, generate a uniformly distributed random number, $\mathrm{t}$, between 0 and 1.

$\circ \quad$ if $p\left(\mathbf{m}_{\text {temp }} \mid \mathbf{C}\right) / p\left(\mathbf{m}_{\mathbf{k}} \mid \mathbf{C}\right)>\mathrm{t}$ or the iteration of Step 2 has reached a predefined maximum number (2000 in this study), accept $\mathbf{m}_{\mathbf{t e m p}}$ as $\mathbf{m}_{\mathbf{k}+\mathbf{1}}$. ○ else, go to Step 2.

206 The set of accepted models converges to the posterior distribution after sufficient numbers of 207 models are collected. However, the exact number can only be determined empirically. In this 208 study, we use the Metropolis-Hastings algorithm to acquire a sample set consisting of at least 2091000 accepted models. There are alternative algorithms to implement MCMC simulations 210 (Robert and Casella, 2004; Liu, 2008). For example, "Gibbs Sampling”, which, in its basic form 211 is a special case of the Metropolis-Hastings algorithm, is more desirable for models with a large 212 number of parameters. Korenaga and Karato (2008) recently used the Gibbs sampling to analyze 213 experimental data on olivine rheology.

214 The result of MCMC simulations following the procedure outlined in the preceding section is 215 a set of accepted models $\left(\mathbf{m}_{\mathbf{0}}, \mathbf{m}_{\mathbf{1}}, \ldots, \mathbf{m}_{\mathbf{n}}\right)$ representing the posterior distribution of model 216 parameters, e.g., $F$ and $\varepsilon$ in the case of disequilibrium fractional melting. Among these models, 217 there is one model called "the most probable model" whose probability in reproducing the 218 observed data is the greatest, designated as $\mathbf{m}_{\mathrm{MP}}=\left(F_{\mathrm{MP}}, \varepsilon_{M P}\right)$ or $\left(F_{\mathrm{MP}}, \varepsilon_{M P}, \alpha_{\mathrm{MP}}\right)$ for the two 219 melting models considered in the next section. In general, the probability distribution of $F$ is not 220 normal or symmetric. To facilitate comparison with normal distribution, we use $\sigma_{-}$and $\sigma_{+}$as 221 lower and upper standard deviation of $F$. The probability that an $F$ randomly chosen from $\left(F_{0}\right.$, $222 F_{1}, \ldots, F_{\mathrm{n}}$, where $F_{\mathrm{i}}$ belongs to $\left.\mathbf{m}_{\mathbf{i}}\right)$ falls into the interval $\left[F_{\mathrm{MP}}-\sigma_{-}, F_{\mathrm{MP}}+\sigma_{+}\right]$is $68 \%$. The 223 procedure for finding $\sigma_{-}$and $\sigma_{+}$is presented in Appendix A. For convenience, we use the notation 
$224 \quad F_{\mathrm{MP}_{-\sigma_{-}}}^{+\sigma_{+}}$to describe the most probable model of $F$ with non-normal posterior distribution. We use 225 this notation for all parameters in the model. In the special case of normal distribution, $\sigma_{-}=\sigma_{+}$. 226 We recover the mean and standard deviation of $F$, viz., $F_{\text {mean }} \pm \sigma$.

227 As for the nonlinear least squares method, the estimate of a model parameter, say $F$, has a 228 symmetric form because the method implicitly assumes a normal distribution of $F$ characterized 229 by the mean $\left(F_{L S}\right)$ and the standard deviation $\left(\sigma_{L S}\right)$. Since the nonlinear least squares method 230 proceeds through iteration to find $F_{\mathrm{LS}}$ which fits the data with the smallest overall residue, $F_{\mathrm{LS}}$ is 231 expected to be the same as $F_{\mathrm{MP}}$ if the iteration converges. The standard deviation obtained by the 232 nonlinear least squares method does not have to be the same as $\sigma_{-}$or $\sigma_{+}$unless the posterior

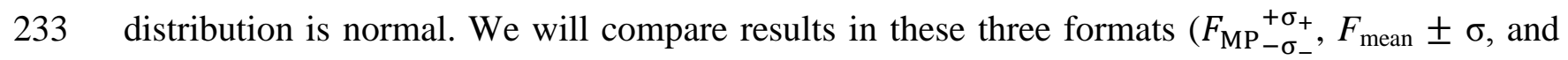
$\left.234 F_{\mathrm{LS}} \pm \sigma_{\mathrm{LS}}\right)$ in a case study in Section 3.2.

236 3. Case Studies

237 3.1. Data and source composition

238 To demonstrate the advantages of the MCMC method, we consider REE and Y abundances 239 in clinopyroxene (cpx) in abyssal peridotites from several mid-ocean ridges. To focus on melting 240 history, we consider residual lherzolites and cpx-bearing harzburgites that show no obvious signs 241 of mantle metasomatism or late stage melt refertilization (i.e., presence of interstitial plagioclase, 242 cross-cutting veins or amphibole; LREE enrichment in cpx; high $\mathrm{TiO}_{2}(>1 \mathrm{wt} \%)$ in spinel, 243 Warren, 2016; see also Section 5.3 for additional discussion). We further choose samples with at 244 least 8 reported trace elements (REE and Y) in cpx. This procedure leads to a data set of 135 245 samples (Table 2, data from Johnson et al., 1990, Hellebrand et al., 2002; Salters and Dick, 2002; 
246 Hellebrand and Snow, 2003; Brunelli et al., 2006; Brunelli and Seyler, 2010; Lassiter et al., 2014;

247 Mallick et al., 2014). Following Liang and Liu (2016), we exclude La in our data if the 248 chondrite-normalized ratio $(\mathrm{La} / \mathrm{Ce})_{\mathrm{N}}$ is too high to be explained by a melting model alone. The 249 melting history of each sample is recorded by multiple incompatible trace element abundances in 250 cpx. Concentrations of the selected trace elements in cpx will be regarded as a data vector $\mathbf{C}$ in 251 MCMC simulations as described in Section 2. We recognize that trace element and isotope 252 compositions of mantle sources beneath mid-ocean ridge spreading centers vary among different 253 ridge systems. For simplicity, we consider melting of the depleted MORB mantle or DMM 254 (Workman and Hart, 2005) in the spinel peridotite field. Liang and Peng (2008) examined the 255 role of garnet field melting and concluded that it is not needed to explain the observed REE 256 patterns in cpx in abyssal peridotites from the Central Indian Ridge (Hellebrand et al., 2002). We 257 consider two disequilibrium melting models: one with an analytical solution and the other 258 without. The former allows us to compare with results from direct nonlinear least squares 259 inversion (Liang and Liu, 2016). The latter melting model is more general as it has one 260 additional model parameter. Our goal in this section is to demonstrate the procedure and 261 advantage of MCMC method through two case studies of a subset of data from the Central 262 Indian Ridge. In Section 4, we further expand case study two by considering trace element data 263 from other mid-ocean ridge systems listed in Table 2.

264 3.2. Case study one: Melting model with an explicit analytical solution

265 Disequilibrium melting happens when diffusion in residual minerals for a trace element of 266 interest cannot keep up with melting of the minerals. It can be characterized by a disequilibrium 267 parameter $\varepsilon$ which is defined as the ratio of melting rate relative to chemical exchange rate, 
$\varepsilon=\frac{\Gamma}{\rho_{s}\left(1-\phi_{f}\right) R}$,

268 where $\Gamma$ and $\rho_{s}$ are the melting rate and density of the bulk solid, respectively; $\phi_{f}$ is the porosity; and $R$

269 is the exchange rate constant. During disequilibrium fractional melting, the concentration of a trace

270 element in residual cpx, $C(\mathbf{m})$, varies as a function of $F$ and $\varepsilon$, and is given by the simple

271 expression (Liang and Liu, 2016),

$C(\mathbf{m})=C_{s}^{0} \frac{k_{c p x}}{k_{0}}\left(1-\frac{\varepsilon+k_{p}}{\varepsilon+k_{0}} F\right)^{\frac{1-k_{p}}{k_{p}+\varepsilon}}$

272 where $C_{\mathrm{s}}^{0}$ is the concentration of the trace element in the mantle source; $k_{0}$ is the bulk partition

273 coefficient at the onset of melting; $k_{\mathrm{p}}$ is the bulk partition coefficient calculated according to

274 melting reaction; and $k_{\mathrm{cpx}}$ is the cpx-melt partition coefficient. Eq. 6 reduces to the familiar

275 equilibrium non-modal perfect fractional melting model when $\varepsilon=0$. For diffusion in solid limited

276 mass transfer, the exchange rate constant $R$ is inversely proportional to the diffusion time scale in the

277 mineral. For spherical grain of radius $d, R$ is given by (e.g., Navon and Stolper, 1987; Bodinier et al., 278 1990),

$R=\frac{15 D}{d^{2}}$

279 where $D$ is the diffusivity of the element of interest in the mineral.

280 A key assumption used to derive Eq. 6 is that the mineral-melt exchange rate constants are 281 the same for all the minerals. For modeling REE fractionation during disequilibrium melting of 282 spinel peridotite, Liang and Liu (2016) demonstrated that it is reasonable to use REE diffusion 283 coefficients in cpx to calculate $R$. Since the disequilibrium parameter of a REE $\left(\varepsilon_{R E E}\right)$ is inversely 284 proportional to its diffusion coefficient (Eqs. 5 and 7), it is convenient to scale $\varepsilon_{R E E}$ for REE and 
$285 \mathrm{Y}$ to that of $\mathrm{La}$ (designated as $\varepsilon_{L a}$ hereafter) according to their diffusion coefficients in cpx 286 (diffusivity data from Van Orman et al., 2002), viz.,

$\varepsilon_{R E E}=\frac{D_{L a}}{D_{R E E}} \varepsilon_{L a}$

287 Liang and Liu (2016) used Eqs. 6 and 8 and a nonlinear least squares method to invert for $F$ and $288 \varepsilon_{L a}$ from REE and Y abundances in cpx in 22 abyssal peridotites from the Central Indian Ridge 289 (CIR, Hellebrand et al., 2002). To compare with their results and to test the new inversion 290 method, here we conduct MCMC simulations for the 22 samples from CIR using the same 291 mineral-melt partition coefficients, diffusion coefficients, melting reaction, and starting mantle 292 composition as in their study. For shorthand notation, we set $\varepsilon=\varepsilon_{L a}$ hereafter. Hence, the model 293 in MCMC simulations has two unknown parameters: degree of melting and extent of 294 disequilibrium for La in cpx, designated as $\mathbf{m}=(F, \varepsilon)$.

295 We choose the prior distribution as a uniform distribution in a two-dimensional model space. 296 In other words, any $\mathbf{m}=(F, \varepsilon)$ in the model space has the same prior probability. The bound for $297 F$ is less than the degree of melting when cpx is exhausted ( $F<18 \%$, Baker and Stolper, 1994). 298 The bound for $\varepsilon$ is [0, 0.05] according to previous inversion results (Liang and Liu, 2016). Figure 2991 displays results of 6231 MCMC simulations for sample ANTP126-2 following the steps 300 outlined in Section 2.2. Here the observed data are shown as yellow circles and each gray line 301 represents an REE pattern calculated using accepted m from MCMC simulations. Those REE 302 patterns predicted by models within the asymmetric confidence interval $\left(\left[F_{M P^{-}} \sigma_{-}, F_{M P}+\sigma_{+}\right]\right.$and $\left.303\left[\varepsilon_{M P}-\sigma_{-}, \varepsilon_{M P}+\sigma_{+}\right]\right)$define a region enclosing the data (Figure 1). The prediction with the most 304 probable model is the best fit to the data (red line in Figure 1). Figures $2 \mathrm{a}$ and $2 \mathrm{~b}$ display 305 marginal distributions of $F$ and $\varepsilon$, respectively. The marginal distribution of $\varepsilon$ is skewed: $\sigma_{+}$of $\varepsilon$ 
306 is larger than $\sigma_{-}$of $\varepsilon$. The normal distribution derived from nonlinear least squares inversion is

307 markedly narrower than the accepted models from MCMC simulations in the histogram. The

308 discrepancy between sample mean and the most probable model also indicates asymmetry of

309 posterior distribution of $\varepsilon$. In a plot of $\varepsilon$ vs. $F$, accepted models scatter around a near elliptical

310 figure centered at the most probable model (Figure 3). Positive trade-off between $F$ and $\varepsilon$ is

311 demonstrated by the NE-SW trend of the accepted models. The ranges of asymmetric uncertainty

312 estimate $\left(\sigma_{+}\right.$and $\sigma_{-}$) are larger than or comparable to the $68 \%$ confidence ellipse for normal

313 distribution. Figures similar to Figures 1-3 for the 22 CIR samples are presented in

314 Supplementary Figure S1. For a few samples, the uncertainty range characterized by $\sigma_{+}$and $\sigma_{-}$

315 is greater than the range of $95 \%$ confidence ellipse derived from direct nonlinear least squares

316 inversion (samples ANTP87-5, ANTP87-9, ANTP89-2, ANTP89-5, ANTP89-8, and ANTP89-

317 15). The nonlinear least squares method cannot describe asymmetric probability distribution of $\varepsilon$

318 and may lead to underestimate of uncertainty.

319 The most probable model derived from MCMC simulations is not necessarily a good fit to 320 the data. The most probable model still cannot fit sample CIRCE93-7 which exhibits a "hump 321 shape" REE pattern. Here the probability of the most probable model is effectively zero ( $p=$ $3221 \times 10^{-14}$ according to Eq. 1-4), which means that the melting model (Eq. 6) cannot explain this

323 sample. A more general model involving refertilization by a small amount of melt produced in

324 the lower part of the melting column, as suggested by Hellebrand et al. (2002), can explain the 325 observed REE data. To avoid samples affected by refertilization and other post-melting 326 processes (discussed in Section 5.3), any sample that has the probability less than $1 \times 10^{-4}$ for the 327 most probable model is excluded in this case study. 
For all samples, the model estimates from nonlinear least squares inversion are consistent

329 with those derived from the most probable model (Figure 4). But the means of accepted models

330 show systematic deviation from the most probable model and the nonlinear least squares results

331 (Figure 4$)$. For $F_{M P}>15 \%, F_{\text {mean }}$ is smaller than $F_{\mathrm{MP}}$ and $F_{\mathrm{LS}}$, whereas for $F_{\mathrm{MP}}<15 \%, \varepsilon_{\text {mean }}$ is

332 greater than $\varepsilon_{M P}$ and $\varepsilon_{L S}$. Since the model represents the most probable physical condition given

333 the data constraint, we recommend using $F_{M P}$ over $F_{\text {mean }}$. For later discussion, the estimate of the

334 model parameter will be presented in the asymmetric form, $F_{M P_{-\sigma_{-}}^{+}}^{+\sigma_{+}}$and $\varepsilon_{M P}^{+\sigma_{+}}$.

335 3.3. Case study two: Melting model without explicit analytical solution

336 The preceding example demonstrates the procedure of MCMC method and its advantage in

337 estimating meaningful uncertainties for model parameters. In this section, we show another

338 important advantage of MCMC method using a disequilibrium dynamic melting model that does

339 not have an explicit analytical solution. Nonlinear least squares inversion of such a problem is

340 challenging, if not impossible. Here we show that MCMC simulation is well suited for this class

341 of inverse problems.

342 The dynamic or continuous melting model has been widely used to study trace element

343 fractionation during mantle melting (e.g., Langmuir et al., 1977; McKenzie, 1985; Zou, 1998;

344 Shaw, 2000). Here we consider a more general case of dynamic melting by allowing chemical

345 disequilibrium between residual minerals and interstitial melt. In nondimensional form, the

346 governing mass conservation equations for a trace element in the interstitial melt $\left(C_{\mathrm{f}}\right)$ and

347 residual solid $\left(C_{\mathrm{s}}\right)$ are given by two coupled ordinary differential equations (a derivation is

348 presented in Appendix B). In terms of the degree of melting, we have 
$(1-F) \varepsilon \alpha \frac{d C_{f}}{d F}=\varepsilon\left(C_{s}^{p}-C_{f}\right)+\left(C_{s}-k C_{f}\right)$

$(1-F) \varepsilon \frac{d C_{s}}{d F}=-\varepsilon\left(C_{s}^{p}-C_{s}\right)-\left(C_{s}-k C_{f}\right)$

$(1-F) \varepsilon \frac{d C_{s}^{j}}{d z}=-\left(C_{s}^{j}-k_{j} C_{f}\right)$

$\alpha=\frac{\rho_{f} \phi_{f} V_{f}}{\rho_{s}\left(1-\phi_{f}\right) V_{s}}$

349 where $\varepsilon$ is defined by Eq. $5 ; \alpha$ is the mass flux ratio between the melt and the residual solid; $C_{s}^{p}$

350 is the concentration of bulk solid calculated according to melting reaction (Eq. B5 in Appendix

$351 \mathrm{~B}) ; k$ is the bulk partition coefficient (Eq. B6); $V_{f}$ is the velocity of the melt; and $V_{s}$ is the

352 upwelling velocity of the solid matrix. To be consistent with equilibrium dynamic melting

353 models of Zou (1998) and Shaw (2000), we assume that dynamic melting starts at $F=f_{p}$ before

354 which melting takes place as equilibrium batch melting. Hence the initial melt and solid

355 compositions at $F=f_{p}$ are

$C_{f}=\frac{C_{S}^{0}}{k_{0}+f_{p}\left(1-k_{P}\right)}$

$C_{S}=\frac{C_{s}^{0}}{k_{0}+f_{p}\left(1-k_{P}\right)} \frac{k_{0}-k_{P} f_{p}}{1-f_{p}}$,

356 where $f_{p}$ is related to $\alpha$ through the simple expression (Shaw, 2000),

$f_{p}=\frac{\alpha}{1+\alpha}$

357 The disequilibrium dynamic melting model has three parameters $(F, \varepsilon, \alpha)$. It recovers the 358 equilibrium dynamic melting when $\varepsilon=0$, the disequilibrium perfect fractional melting when $\alpha=$ 359

0 . For an incompatible trace element, its concentration in residue at a given $F$ increases with $\alpha$ or 
$360 \varepsilon$ (Liang and Liu, 2016). Since there is no explicit analytical solution to Eqs. 9-11, here we invert 361 the melting parameters through MCMC simulations. Our observations include REE and Y 362 abundances in cpx in the 22 abyssal peridotites from CIR. We solve Eqs. 9-11 numerically using 363 the third-order Runge Kutta method (Shu and Osher, 1988), starting from the initial conditions 364 prescribed by Eqs. 13 and 14.

365 The prior bounds for model parameters are $f_{p}<F<0.18,0.0002<\varepsilon<0.05$, and $0.0005<\alpha<$ 366 0.04. The upper bound for $F$ and $\varepsilon$ are the same as in case study one. The lower bound for $F$ is 367 the onset of dynamic melting (Eq. 15). The upper bound for $\alpha$ is equivalent to a scenario in 368 which there is $2 \%$ porosity and the melt percolates two times faster than the solid. The non-zero 369 lower bounds for $\varepsilon$ and $\alpha$ are for the consideration of numerical stability in solving Eqs. 9-11. 370 These upper and lower bounds are conservative with respect to the most probable models.

371 Figure 5 shows results of MCMC simulations for three samples: one with effectively zero $\alpha$ 372 (ANTP126-2), one with effectively zero $\varepsilon$ (ANTP89-1), and one with intermediate $\alpha$ and $\varepsilon$ 373 (sample CIRCE93-4). These model parameters are not from normal distributions. Figure 6 374 displays the asymmetric marginal distributions of $F, \varepsilon$, and $\alpha$ for sample ANTP126-2. The most 375 probable model deviates from the peak of marginal distribution as a result of $3 \mathrm{D}$ to $1 \mathrm{D}$ projection. 376 This is further illustrated in Figure 7 for the three samples displayed in Figure 5. Even when 377 projected on $F-\varepsilon$ and $\varepsilon-\alpha$ planes, accepted models as points of $\mathbf{m}=(F, \varepsilon, \alpha)$ clearly display 378 nonlinear trade-offs. There is a broad negative correlation between $\varepsilon$ and $\alpha$ in Figures $7 \mathrm{~b}, 7 \mathrm{e}$ and 3797 h. The distribution near the origin on the $\varepsilon-\alpha$ plane is considerably sparser than the region 380 where $\alpha$ and $\varepsilon$ are greater than 0.01 (Figure 7b). Thus, equilibrium fractional melting is unlikely 381 for sample ANTP126-2. Further, the $\varepsilon-\alpha$ correlation is not characterized by an ellipse expected 382 in a bimodal normal distribution. The probability distribution is denser near the $\varepsilon$ axis than near 
383 the $\alpha$ axis (Figure 7b). The most probable model has small $\alpha$ and relatively large $\varepsilon$, which is 384 clearly shown in Figure 7c. Therefore, sample ANTP126-2 is better represented by a model that 385 is closer to disequilibrium fractional melting than equilibrium dynamic melting. (The converse is 386 true for sample 89-1.) Figures 7d-7f are from a model with both $\varepsilon$ and $\alpha$ greater than 0.01 , an 387 intermediate case that cannot be represented by known analytical solutions (i.e., disequilibrium 388 factional melting model $(\alpha=0, \varepsilon>0)$ or equilibrium dynamic melting model $(\varepsilon=0, \alpha>0))$. The 389 estimate of $\varepsilon$ in case study one only considers the $\alpha=0$ plane in $F-\varepsilon-\alpha$ space. Because there 390 exist trade-offs between $\varepsilon$ and $\alpha$, case study one would overestimate $\varepsilon$. The trade-off between the 391 extent of disequilibrium and the extent of incomplete melt extraction has been noted in previous 392 studies (Qin, 1992; Iwamori, 1993b; Van Orman et al., 2002). The preceding examples 393 demonstrate that with MCMC simulations it is possible to target the most probable combination 394 of $\varepsilon$ and $\alpha$ for an individual sample. Similar figures summarizing MCMC simulations for all the 395 samples included in this study are presented in Supplementary Figure S2. Melting parameters 396 from the most probable model are summarized in Supplementary Table S1.

397 Figure 8 compares results from case studies one and two for the CIR samples. In general, $\varepsilon$ 398 estimated in case study two (unfilled circles) are smaller, especially for those samples with $F$ less 399 than $13 \%$. This is largely due to the negative trade-off between $\varepsilon$ and $\alpha$ in the disequilibrium 400 dynamic melting model, i.e., the product $\varepsilon \alpha$ in Eq. 9. The lower values of $\varepsilon$ in the disequilibrium 401 dynamic melting model are compensated by $\alpha$ which is absent in the disequilibrium perfect 402 fractional melting model. (For the same reason, values of $\alpha$ derived from the equilibrium 403 dynamic melting model would be higher than values obtained from the disequilibrium dynamic 404 melting model.) Therefore, values of $\varepsilon$ derived from the more general melting model in case 
study two are more reliable than values derived from the disequilibrium fractional melting model

406 in case study one and the equilibrium dynamic melting model.

\section{Application to Abyssal Peridotites from other Selected Mid-Ocean Ridge Systems}

410 and $\varepsilon$ derived from nonlinear least squares inversion of REE and $Y$ abundances in cpx in abyssal

411 peridotites from CIR using the disequilibrium fractional melting model (Liang and Liu, 2016).

412 This positive correlation is further confirmed in the present study through the application of the

413 more general disequilibrium dynamic melting model (Figures 8 and 9d). An interesting question

414 is if similar correlation between $F$ and $\varepsilon$ also exists in abyssal peridotites from other mid-ocean

415 ridge systems. In this section, we expand case study two to include peridotites from the Vema

416 Lithospheric Section (VLS, 35 samples, Brunelli et al., 2006), Kane Fracture Zone and Saint

417 Paul Fracture Zone (KSP, 9 samples, Brunelli and Seyler, 2010; Mallick et al., 2014) at the Mid-

418 Atlantic Ridge, the South West Indian Ridge (SWIR, 35 samples, Warren, 2007), Lena Trough at

419 the Arctic Ocean (LT, 25 samples, Hellebrand and Snow, 2003; Lassiter et al., 2014), and the

420 American-Antarctica Ridge (AAR, 9 samples, Johnson et al., 1990). The spreading rates of

421 SWIR, LT, and AAR $(<20 \mathrm{~mm} / \mathrm{yr})$ are slower than CIR $(30-51 \mathrm{~mm} / \mathrm{yr})$, while the spreading

422 rates of VLS and KSP at Mid-Atlantic Ridge (25-31 mm/yr) are at the lower end of CIR (Argus

423 and Gordon, 1991; DeMets et al., 2010).

424 Supplementary Table S1 summarizes results from MCMC simulations based on the 425 disequilibrium dynamic melting model (Eqs. 9-15). Supplementary Figures S2 present MCMC 426 simulations of individual samples. Similar to case study one, samples with poor fit are excluded 
427 according to a threshold probability. As a result of this filtering, thirty-four out of 135 samples

428 are disqualified. REE abundances in these samples are likely affected by secondary processes

429 such as melt refertilization (see Section 5.3 for additional discussion). As a precaution, we

430 exclude these samples in the interpretation of the disequilibrium dynamic melting model. If we

431 only consider the most probable model, samples from all mid-ocean ridge systems considered in

432 this study except two from SWIR (samples EDUL-6B-1-3 and EDUL-23-2-8 from Seyler et al.,

433 2011) show a positive correlation between $\mathrm{F}$ and $\varepsilon$ for La, although the range of variation differs

434 among localities (Figure 9). The lower bound of $\varepsilon$ for these two samples still lie on the trend of

435 the rest of 25 samples from SWIR (magenta squares in Figure 9a). A model on the $F-\varepsilon$ trend 436 still produces an acceptable fit (Figure 9 and Figure S2). Samples from SWIR and CIR show 437 strong positive trends even when uncertainties are considered (Figures 9a and 9d).

439 5. Discussion

$440 \quad$ 5.1. The positive correlation between $F$ and $\varepsilon$

441 We have demonstrated in the preceding sections that the positive correlations between $F$ 442 and $\varepsilon$ for La in cpx in abyssal peridotites is a robust feature of mantle melting beneath mid-ocean 443 ridge spreading centers. The disequilibrium parameter $\varepsilon$ is defined as the ratio of the melting rate 444 to the solid-melt diffusive exchange rate for La in cpx (Eq. 5). The melting rate is proportional to 445 solid upwelling rate $\left(V_{s}\right)$ and melt productivity $(d F / d z)$ along the melting column. The diffusive 446 exchange rate is inversely proportional to the time scale of La diffusion in cpx (Eq. 8). Liang and 447 Liu (2016) presented a simple equation relating $\varepsilon$ to these parameters for a steady-state melting 448 column, viz., 
$\varepsilon_{L a}=\frac{V_{S} d^{2}}{15(1-F) D_{L a}} \frac{d F}{d z}$

449 where $D_{L a}$ is the diffusivity of the trace element of interest (La) in cpx. In the calculation below, 450 we take $V_{s}$ as half of the local spreading rate (Argus and Gordon, 1991; DeMets et al., 2010). 451 The disequilibrium parameter $\varepsilon$ is very sensitive to cpx grain size (Eq. 16). There are 452 considerable uncertainties in cpx grain size and its size distribution in the starting mantle. Since 453 our goal here is to understand the positive correlation between $F$ and $\varepsilon$, we compare melting 454 models with the same cpx grain size at the onset of melting $(d=1.5 \mathrm{~mm})$. Furthermore, we 455 assume that the average grain size of cpx decreases in proportion to cpx volume reduction during 456 melting.

Asimow et al. $(1997,2001)$ demonstrated that one can use the thermodynamic model 458 MELTS to calculate melt productivity along a melting column. Figure 10 displays calculated 459 disequilibrium parameters for La $\left(\varepsilon_{L a}\right)$ along three melting paths using pMELTS (Ghiorso et al., 460 2002; Smith and Asimow, 2005) for anhydrous melting of a DMM source (Workman and Hart, 461 2005). The calculated $\varepsilon_{L a}$ is smaller for higher potential temperature as a result of strong 462 temperature dependent diffusivity. The disequilibrium parameter $\varepsilon_{L a}$ varies by one order of 463 magnitude over the range of potential temperatures considered $\left(1280^{\circ} \mathrm{C}\right.$ to $\left.1340^{\circ} \mathrm{C}\right)$. The increase 464 of $\varepsilon_{L a}$ at lower $F$ is due to increasing melt productivity and decreasing diffusion rate, while the 465 decrease of $\varepsilon_{L a}$ at higher $F$ is due to grain size reduction of cpx during melting. The latter is not 466 well constrained. In a more realistic case where cpx has a range of grain size in the starting 467 mantle, it is possible that smaller cpx grains will be preferentially consumed earlier during 468 melting than larger grains. Hence the decrease in predicted $\varepsilon_{L a}$ along a given mantle adiabat may 469 be less that shown in Figure 10 for uniform cpx grain size distribution at higher degrees of 
470 melting (e.g., $F>14 \%$ ). In case study two, we assume $\varepsilon_{L a}$ to be constant along the melting

471 column. Thus the inverted $\varepsilon$ should be regarded as an average value during disequilibrium

472 melting. For comparison, we also calculate the average of $\varepsilon_{L a}$ at a given $F$ as the arithmetic mean

473 of $\varepsilon_{L a}$ from the onset of melting to $F$. Figure 10 shows that the average $\varepsilon_{L a}$ (dashed lines)

474 increases but lags behind the instantaneous $\varepsilon_{L a}$ at lower $F$. As $F$ further increases, the average $\varepsilon_{L a}$

475 levels off. In spite of uncertainties in cpx grain size, grain size variation and distribution, the 476 positive correlations between the inverted $\varepsilon$ and $F$ shown in Figures 9a-9d are consistent with the

477 predicted correlation between $\varepsilon_{L a}$ and $F$ at a given mantle potential temperature (Figure 10).

478 5.2. Variation of $\varepsilon$ at a given $F$

479 There are considerable variations of $\varepsilon$ for La at a given $F$ among samples from the same 480 ridge segments and between samples from different ridges (Figure 9). Possible factors 481 responsible for the observed variations of $\varepsilon_{L a}$ at a given $F$ include, but are not limited to (see 482 Section 5.3 below), grain size variation among segments, grain size distribution in a single 483 segment, upwelling rate, and potential temperature. In the following discussion, "variation in $\varepsilon "$ 484 refers to "variations of $\varepsilon$ at a given $F$ " unless stated otherwise. We first consider variations of $\varepsilon$ 485 among different ridge segments by normalizing inverted data shown in Figure 9 with respect to 486 the upwelling rate.

487 According to Eq. 16, $\varepsilon_{L a}$ is proportional to local upwelling rate (and hence spreading rate). 488 Thus the inverted $\varepsilon$ from ridges of different spreading rate are not directly comparable. To 489 facilitate comparison, we renormalize $\varepsilon$ from different ridges to a common or reference 490 spreading rate $V_{0}(=30 \mathrm{~mm} / \mathrm{yr})$. The results are shown in Figure 10. If the variation in $\varepsilon$ is due to 491 upwelling rate alone, Figure 10 would plot all scaled inversion results on the same trend. But this 
492 is not the case. High $\varepsilon$ and low $F$ is common for samples from ridges with ultra-slow spreading

493 rate (SWIR, LT, and AAR), while ridges with intermediate spreading rate (CIR) show lower $\varepsilon$ 494 and higher $F$. Two data sets from the slow spreading Mid-Atlantic Ridge (VLS and KSP) plot 495 between CIR and ultra-slow spreading ridges. This is further illustrated in Figure $11 \mathrm{~b}$ where 496 samples with large $\varepsilon / F$ ratios are from ultra-slow spreading ridges (SWIR, LT, AAR), while 497 samples with small $\varepsilon / F$ ratios are from intermediate-slow spreading ridges (CIR).

498 Different local $F-\varepsilon$ trends suggest factors other than upwelling rate contribute to the bulk 499 of the variation in $\varepsilon$. In general, $\varepsilon / F$ increases with grain size and decreases with potential 500 temperature. A reduction of potential temperature from $1310^{\circ} \mathrm{C}$ to $1280^{\circ} \mathrm{C}$ can explain the three501 fold variation in $\varepsilon$ at a given $F$ (Figure 10). If the average $\varepsilon / F$ is due to potential temperature 502 while the scatter is due to grain size variation, the negative trend of $\varepsilon / F$ vs. spreading rate in 503 Figure 11 could be understood in terms of a positive correlation between the spreading rate and 504 the potential temperature. Interestingly, the average degree of melting in each bin of spreading 505 rate is positively correlated with spreading rate (Figure 11a). This positive correlation between $F$ 506 and spreading rate has been attributed to deeper final melting depth at slower spreading ridge as 507 a result of strong conductive cooling compared to adiabatic upwelling (White and Brown, 1994; 508 Niu and Hékinian, 1997). Results from the present study suggest that 7\% more melting of CIR 509 compared to SWIR (Figure 11a) at faster spreading ridges could also be partly due to deeper 510 initial melting depth as a result of the $30^{\circ} \mathrm{C}$ higher potential temperature.

511 A reduction of potential temperature from $1310^{\circ} \mathrm{C}$ to $1280^{\circ} \mathrm{C}$ can explain the observed 512 difference in $\varepsilon$ between SWIR and CIR (Figures 9 and 10). Such variations in potential 513 temperature agree with the ranges of potential temperature inferred from independent studies 514 (Niu and O'Hara, 2008; Dalton et al., 2014). Many abyssal peridotite samples are from fracture 
515 zones. In Marie Celeste Fracture Zone in CIR, three-fold difference of $\varepsilon$ exists within $10 \mathrm{~km}$

516 (ANTP89-5: $\varepsilon_{M P}=0.006_{-0.004}^{+0.006}$, and ANTP87-9: $\varepsilon_{M P}=0.021_{-0.005}^{+0.006}$ ). Along the Vema

517 Lithospheric Section at Mid-Atlantic Ridge, the most probable $\varepsilon$ appears to vary randomly

518 between 0.0002 and 0.03 (Figure 12), although the uncertainty does not exclude a constant $\varepsilon$.

519 Such local variation of $\varepsilon$ could, in part, be attributed to temperature perturbation associated with

520 transform fault (Morgan and Forsyth, 1988; Roland et al., 2010). If the most probable $\varepsilon$ indeed

521 increases 10 fold along this $250 \mathrm{~km}$ long fracture zone, this would require a temperature increase

522 of $\sim 60{ }^{\circ} \mathrm{C}$. The temperature induced variation of $\varepsilon$ is limited by the smoothing effect of thermal

523 diffusion. If the observed variation in $\varepsilon$ is due to potential temperature alone, the temperature

524 profile of one sample during melting may be $30{ }^{\circ} \mathrm{C}$ higher than the temperature profile of another

525 sample $10 \mathrm{~km}$ away. In a thermal model of transform fault (Morgan and Forsyth, 1988; Roland et

526 al., 2010), sharp horizontal temperature gradient is difficult to extend to the depth of initial

527 melting. Therefore temperature can only account for smooth inter-ridge and along-fault

528 variations in $\varepsilon$.

529 The disequilibrium parameter $\varepsilon_{L a}$ is very sensitive to grain size (Eq. 16). For the abrupt

530 along-fault variation in $\varepsilon$ (Figure 12), variation or heterogeneity in grain size is a simple

531 explanation. Unfortunately, clinopyroxene which is the dominant host for REE in spinel

532 peridotites is almost exhausted in residual abyssal peridotites (Warren, 2016; and references

533 therein). If the grain size is extrapolated back to the source, the uncertainty is expected to

534 increase further. Here, we provide an estimate of initial grain size of cpx by attributing the local

535 variation of $\varepsilon$ at a given $F$ solely to grain size variation after correction for upwelling rate. The

536 factor that regresses inverted data to each predicted melting trend shown in Figure 10 is 
537 proportional to the grain size squared according to Eq. 16. Thus, the grain size of the source is

538 derived for each sample at a presumed potential temperature,

$$
d=\sqrt{\frac{\varepsilon_{L a} \cdot V_{0} / V_{s p}}{\varepsilon_{T p}^{0}}} \cdot d_{0},
$$

539 where $\varepsilon_{T p}^{0}$ is the average $\varepsilon_{L a}$ calculated along a melting path with potential temperature $T_{p}$ and 540 reference grain size $\left(d_{0}=1.5 \mathrm{~mm}\right)$ and reference upwelling rate $\left(\mathrm{V}_{0}=15 \mathrm{~mm} / \mathrm{yr}\right)$.

541 Only samples from the VLS at MAR (Brunelli et al., 2006) and the Marie Celeste TF at

542 CIR (Hellebrand et al., 2002) are used to estimate the average grain size because there is a 543 relatively large dataset within a single transform fault (26 in VLS and 9 in Marie Celeste TF)

544 where we assume the potential temperature is constant. Figure 13 demonstrates that larger grain

545 size is required to compensate faster diffusion at higher potential temperature. Given three

546 choices of potential temperature, the average grain size ranges from $0.56 \mathrm{~mm}$ to $2.55 \mathrm{~mm}$ at

547 these two locations. The grain size distribution at these two locations cannot be discriminated

548 statistically given the same potential temperature. In other words, there could be no difference in

549 grain size and potential temperature between these two locations although the spreading rates

550 between the two are somewhat different (Marie Celeste TF, $41 \mathrm{~mm} / \mathrm{yr}$; VLS, $28 \mathrm{~mm} / \mathrm{yr}$ ). The

551 average grain size corresponding to each potential temperature is distinct. The potential

552 temperature or the average grain size could be estimated given the knowledge of the other.

\section{5.3. Other processes or factors}

554 A number of factors or processes not considered in the preceding discussion can also affect 555 trace element abundances in residual cpx: (1) source heterogeneity, (2) shallow level 556 refertilization, and (3) subsolidus reequilibration. In Liang and Liu (2016), we assessed the 
557 effects of (1) and (2) using available Nd isotope data from VLS (12 samples). Figure 14 includes

5587 additional samples from SWIR, Kane Fracture Zone, and Saint Paul Fracture Zone. There is no

559 obvious correlation between $\varepsilon$ and ${ }^{143} \mathrm{Nd} /{ }^{144} \mathrm{Nd}$, suggesting that mantle source heterogeneity in

560 REE is not an important factor controlling the variation of $\varepsilon$. It is possible that source

561 heterogeneities in major element composition (hence mineral proportion) and cpx grain size also

562 contribute to the observed variations in $\varepsilon$. The former can affect the absolute value of $F$ inverted

563 from the REE data, while the latter has a strong effect on the interpretation of inverted $\varepsilon$ (cf. Eq.

564 16). There are considerable uncertainties in both. As a first application of MCMC inversion of

565 REE data in residual cpx, our assumption of a DMM initial composition is a reasonable starting

566 point. The size of cpx grains in peridotite is not uniform. During partial melting, smaller cpx

567 grains are likely consumed first. Our inverted $\varepsilon$ is likely weighed towards larger cpx grains that

568 control the time scale of diffusive reequilibration between $\mathrm{cpx}$ and residual melt. The roles of

569 mantle source heterogeneity and cpx grain size distribution are subjects of future investigations.

570 Shallow level refertilization by small degree melt produced in the lower part of the melting

571 column has been suggested by Hellebrand et al. (2002) and Brunelli et al. (2006) to account for

572 elevated LREE patterns in residual cpx in some abyssal peridotites from CIR and VLS. We note

573 that refertilization can account for the $34 \mathrm{cpx}$ samples excluded in this study (for examples see

574 Hellebrand et al, 2002; Brunelli et al, 2006; Liang and Liu, 2016).

575 Elevated HREE patterns in residual cpx in abyssal peridotites have often been attributed to 576 garnet field melting. According to Sun and Liang (2014), HREE in cpx could be elevated by a 577 factor of 2 during subsolidus exchange with orthopyroxene in spinel harzburgite at low 578 temperatures. A correction of HREE to lower values could increase the estimate of $F$ because 
579 HREE are more depleted than they appear. The estimate of $\varepsilon$ could also increase because there

580 will be more LREE enrichment relative to HREE (see Figure 5 in Liang and Liu, 2016).

\section{Summary and outlook}

The present study is motivated primarily by the positive correlation between $F$ and $\varepsilon$ derived 584 from nonlinear least squares inversion of REE and $\mathrm{Y}$ abundances in cpx in abyssal peridotites 585 from CIR using the disequilibrium perfect fractional melting model. To test the robustness of this 586 correlation for melting beneath mid-ocean ridge spreading centers, we used a more general 587 melting model to better assess uncertainties of inverted melting parameters. Most physically 588 more realistic melting models for trace elements do not have explicit analytical solutions, which 589 poses a considerable challenge to inversion of melting parameters through nonlinear least 590 squares analysis of REE data in residual cpx. This led us naturally to the MCMC method. Here

591 we demonstrated the method of MCMC simulations and its advantages in studying geochemical 592 inverse problems through two case studies of disequilibrium mantle melting. We introduced 593 MCMC method to interpret geochemical observations as consequences of the model with 594 unknown physical parameters. We showed that melting parameters inverted through MCMC 595 simulations are consistent with those obtained from direct nonlinear least squares inversions. 596 However, the nonlinear least squares method cannot describe the asymmetric posterior 597 distribution. The uncertainty derived from nonlinear least squares method could be 598 underestimated compared to the MCMC method.

599 Reading melting parameters from REE data in cpx in abyssal peridotites through MCMC 600 simulations of disequilibrium dynamic melting has led new insights into the melting processes 
601 beneath mid-ocean ridge spreading centers. We found that the disequilibrium dynamic melting 602 model (Eqs. 9-11) can explain REE patterns in cpx in 75\% residual abyssal peridotite samples 603 considered in this study (101 out of 135). The positive correlation between $F$ and $\varepsilon_{L a}$ has been 604 confirmed by the disequilibrium dynamic melting model and additional data from several ultra605 slow to intermediate spreading centers around the world. We suggest that the positive correlation 606 between $F$ and $\varepsilon_{L a}$ is a natural consequence of decompressional melting beneath mid-ocean ridge 607 spreading centers (i.e., a continuous competition between melting and diffusive exchange 608 between the minerals and the melt). More isotope and petrological data are needed to assess the 609 role of mantle source heterogeneity on the variations of $\varepsilon_{L a}$ at a given $F$. The variation in $\varepsilon_{L a}$ at a 610 given $F$ is probably not caused by variations in upwelling velocity or spreading rate alone. The 611 combination of potential temperature and grain size distribution of cpx can explain the $\varepsilon_{L a}-F$ 612 correlations, although additional factors and processes such as mantle source heterogeneity, 613 shallow level refertilization, and subsolidus reequilibration may also contribute to the observed 614 REE patterns in the peridotites.

615 For the purpose of demonstration, we considered two simple disequilibrium fractional 616 melting models by assuming constant mineral-melt REE partition coefficients and diffusion 617 coefficients, by treating non-modal melting as a simple melting reaction with constant 618 coefficients, and by simplifying the physics of melt extraction with a constant porosity or melt619 to-solid mass flux ratio (i.e., the steady-state dynamic melting model). These assumptions and 620 simplifications, which have been widely used in geochemical studies of mantle melting, can be 621 relaxed or eliminated within the framework of MCMC which does not require explicit analytical 622 solutions for the conservation equations. This unique feature of MCMC allows us to use self623 consistent melting models to better constrain melting parameters from trace element abundances 
624 in residual minerals and basalts in future studies. For example, in a more realistic scenario of

625 adiabatic mantle melting, one can use a thermodynamic model to calculate residual mineral

626 proportions and major element compositions along a melting path. Results from the

627 thermodynamic modeling can be used to calculate temperature-, pressure- and mineral

628 composition-dependent mineral-melt REE partition coefficients and diffusion coefficients based

629 on parameterized lattice strain models for REE partitioning and Arrhenius relations for REE

630 diffusion in pyroxenes. Furthermore, for the one-dimensional steady-state problem considered in

631 this study, it is also straightforward to include the physics of melt migration as part of the

632 MCMC simulations. The melt fraction, melt and solid velocities, and melting rate are related to

633 each other through mass, momentum and energy conservation equations (e.g., McKenzie, 1984;

634 Ribe, 1985; Šrámek et al., 2007; Hewitt and Fowler, 2008). One of the advantages of MCMC

635 methods is that we do not have to know the exact values of porosity and velocity a priori. The

636 uncertainties in these physical parameters can be circumvented by solving forward models with a

637 range of values. The data automatically converge those parameters to the most probable values.

638 With ever increasing computing power and geochemical and geophysical data, it is possible to

639 study a wide range of physically and chemically realistic melting problems through MCMC

640 simulations.

\section{ACKNOWLEDGMENTS}

643 We would like to thank Don Forsyth for advice on MCMC method, Reid Cooper and Greg 644 Hirth for discussion regarding clinopyroxene grain size in mantle rocks, and Nick Dygert for a 645 careful reading of an earlier version of this paper. This paper benefited from thoughtful review comments by Paul Asimow, Haibo Zou, an anonymous reviewer, and the associate editor Dmitri 
647 Ionov. This work was supported by US National Science Foundation grants OCE-115567 and 648 EAR-1624516.

Appendix A. Procedure for finding $\sigma_{-}$and $\sigma_{+}$for parameter $F$ from a set of accepted models

$\sum_{j=i}^{100} p F\left(F_{b p j}\right) \leq 68 \% \cdot \sum_{j=1}^{100} p_{F}\left(F_{b p j}\right)$.

657 The minimum and maximum among $\left(\mathrm{F}_{\mathrm{bpi}}, \mathrm{F}_{\mathrm{bp} 2}, \ldots, \mathrm{F}_{\mathrm{bp} 100}\right)$ are $\mathrm{F}_{\text {lower }}$ and $\mathrm{F}_{\mathrm{upper}}$ respectively.

658 Finally, we obtain $\sigma_{-}$and $\sigma_{+}$for parameter $\mathrm{F}$ as:

$\sigma_{-}=F_{M P}-F_{\text {lower }}$ or 0 if $F_{M P}<F_{\text {lower }}$,

$\sigma_{+}=F_{\text {upper }}-F_{M P}$ or 0 if $F_{M P}>F_{\text {upper }}$,

659 where $F_{M P}$ is the $F$ of the most probable model $\mathbf{m}_{\mathbf{M P}}$ among $\left(\mathbf{m}_{\mathbf{0}}, \mathbf{m}_{\mathbf{1}}, \ldots, \mathbf{m}_{\mathbf{n}}\right)$.

661 Appendix B. Derivation of the disequilibrium dynamic melting model

662 We consider trace element fractionation during disequilibrium melting and melt migration in 663 a one-dimensional steady-state upwelling column in which part of the melt generated is extracted 664 to nearby channels or conduits. At steady state, mass conservation equations for a non- 
665 radioactive trace element in the interstitial melt, residual solid, and a given mineral in the 666 upwelling matrix are (Liang and Liu, 2016),

$$
\begin{aligned}
& \rho_{f} \phi_{f} V_{f} \frac{d C_{f}}{d z}=\Gamma\left(C_{s}^{p}-C_{f}\right)+\rho_{s}\left(1-\phi_{f}\right) \sum_{j=1}^{N} w_{j} R_{j}\left(C_{s}^{j}-k_{j} C_{f}\right), \\
& \rho_{s}\left(1-\phi_{f}\right) V_{s} \frac{d C_{s}}{d z}=\Gamma\left(C_{s}-C_{s}^{p}\right)-\rho_{s}\left(1-\phi_{f}\right) \sum_{j=1}^{N} w_{j} R_{j}\left(C_{s}^{j}-k_{j} C_{f}\right), \\
& \rho_{s}\left(1-\phi_{f}\right) V_{s} \frac{d C_{s}^{j}}{d z}=-\rho_{s}\left(1-\phi_{f}\right) R_{j}\left(C_{s}^{j}-k_{j} C_{f}\right), \\
& C_{s}=\sum_{j=1}^{N} x_{j} C_{s}^{j}, \quad C_{s}^{p}=\sum_{j=1}^{N} p_{j} C_{s}^{j}, \quad k=\sum_{j=1}^{N} w_{j} k_{j},
\end{aligned}
$$

667 where $w_{j}$ is the weight fraction of mineral $j$ in residual solid; $R_{j}$ is the exchange rate constant for 668 the trace element of interest between mineral $j$ and the melt; $k_{j}$ is the mineral $\mathrm{j}$ and melt partition 669 coefficient for the trace element. Definitions of other symbols are listed in Table 1. The first 670 terms on the right-hand side (RHS) of Eqs. B1-B2 account for non-modal melting of the solid 671 (the melting term in Eq. B3 is cancelled out by mass conservation constraint). The second terms 672 on the RHS of Eqs. B1-B2 are due to finite rates of mineral-melt mass transfer in the partially 673 molten system. For simplicity, we neglect diffusion and dispersion in the melt and use linear 674 kinetics to approximate crystal-melt finite exchange that arises from diffusion in minerals and/or 675 dissolution-reprecipitation (Navon and Stolper, 1987; Richter and DaPaolo, 1987; Bodinier et al., 676 1990; Liang, 2003).

677 The degree of melting experienced by the solid matrix is given by the material derivative 678 (Liang and Peng, 2010), 
$V_{s} \frac{d F}{d z}=\frac{(1-F) \Gamma}{\rho_{s}\left(1-\phi_{f}\right)}$

679 where the factor $(1-F)$ accounts for the fraction of solid remaining. For the one-dimensional 680 problem considered here, we can rewrite the mass conservation equations in terms of the degree 681 of melting via Eq. B6 using the chain rule, viz.,

$\frac{d C}{d z}=\frac{d C}{d F} \frac{d F}{d z}=\frac{(1-F) \Gamma}{\rho_{s}\left(1-\phi_{f}\right) V_{S}} \frac{d C}{d F}$

682 Substituting Eq. B7 into Eqs. B1-B3, we have a set of conservation equations relating 683 concentrations to the degree of melting experienced by the solid matrix,

$$
\begin{aligned}
& \frac{\rho_{f} \phi_{f} V_{f}}{\rho_{s}\left(1-\phi_{f}\right) V_{s}}(1-F) \Gamma \frac{d C_{f}}{d F}=\Gamma\left(C_{s}^{p}-C_{f}\right)+\rho_{s}\left(1-\phi_{f}\right) \sum_{j=1}^{N} w_{j} R_{j}\left(C_{s}^{j}-k_{j} C_{f}\right), \\
& (1-F) \Gamma \frac{d C_{s}}{d F}=\Gamma\left(C_{s}-C_{s}^{p}\right)-\rho_{s}\left(1-\phi_{f}\right) \sum_{j=1}^{N} w_{j} R_{j}\left(C_{s}^{j}-k_{j} C_{f}\right), \\
& (1-F) \Gamma \frac{d C_{s}^{j}}{d F}=-\rho_{s}\left(1-\phi_{f}\right) R_{j}\left(C_{s}^{j}-k_{j} C_{f}\right),
\end{aligned}
$$

684 For constant melting rate and melt-to-solid mass flux ratio (i.e., in a case of dynamic melting), 685 Eqs. B9-B11 can be further simplified by dividing each equation by the product $\rho_{s}\left(1-\phi_{f}\right) R_{1}$, 686 viz.,

$$
\alpha \varepsilon_{1}(1-F) \frac{d C_{f}}{d F}=\varepsilon_{1}\left(C_{s}^{p}-C_{f}\right)+\sum_{j=1}^{N} w_{j} \frac{R_{j}}{R_{1}}\left(C_{s}^{j}-k_{j} C_{f}\right)
$$




$$
\begin{aligned}
& \varepsilon_{1}(1-F) \frac{d C_{s}}{d F}=\varepsilon_{1}\left(C_{s}-C_{s}^{p}\right)-\sum_{j=1}^{N} w_{j} \frac{R_{j}}{R_{1}}\left(C_{s}^{j}-k_{j} C_{f}\right), \\
& \varepsilon_{1}(1-F) \frac{d C_{s}^{j}}{d F}=-\frac{R_{j}}{R_{1}}\left(C_{s}^{j}-k_{j} C_{f}\right),
\end{aligned}
$$

687 where $\alpha$ is the melt-to-solid mass flux ratio (Eq. 12); $\varepsilon_{1}$ is the disequilibrium parameter defined 688 with respect to the exchange rate constant for the element of interest in mineral 1 ,

$\varepsilon_{1}=\frac{\Gamma}{\rho_{s}\left(1-\phi_{f}\right) R_{1}}$.

689 When $R_{1}=R_{2}=\ldots=R_{\mathrm{N}}=R$, Eqs. B12-B14 reduce to Eqs. 9-11 which are the working model 690 in this study. 
Albarède, F. (1995) Introduction to Geochemical Modeling. Cambridge University Press.

Allegre, C. and Minster, J. (1978) Quantitative models of trace element behavior in magmatic processes. Earth and Planetary Science Letters 38, 1-25.

Anders, E. and Grevesse, N. (1989) Abundances of the elements: Meteoritic and solar. Geochimica et Cosmochimica Acta 53, 197-214.

Argus, D.F. and Gordon, R.G. (1991) No-net-rotation model of current plate velocities incorporating plate motion model NUVEL-1. Geophysical Research Letters 18, 2039-2042.

Asimow, P.D., Hirschmann, M.M. and Stolper, E.M. (1997) An analysis of variations in isentropic melt productivity. Philosophical Transactions of the Royal Society of London A: Mathematical, Physical and Engineering Sciences 355, 255-281.

Asimow, P.D., Hirschmann, M.M. and Stolper, E.M. (2001) Calculation of Peridotite Partial Melting from Thermodynamic Models of Minerals and Melts, IV. Adiabatic Decompression and the Composition and Mean Properties of Mid-ocean Ridge Basalts. Journal of Petrology 42, 963-998.

Backus, G. and Gilbert, F. (1968) The resolving power of gross earth data. Geophysical Journal of the Royal Astronomical Society 16, 169-205.

Baker, M.B. and Stolper, E.M. (1994) Determining the composition of high-pressure mantle melts using diamond aggregates. Geochimica Et Cosmochimica Acta 58, 2811-2827.

Bodinier, J.L., Vasseur, G., Vernieres, J., Dupuy, C. and Fabries, J. (1990) Mechanisms of Mantle Metasomatism: Geochemical Evidence from the Lherz Orogenic Peridotite. Journal of Petrology 31, 597-628.

Bown, J.W. and White, R.S. (1994) Variation with spreading rate of oceanic crustal thickness and geochemistry. Earth and Planetary Science Letters 121, 435-449.

Brunelli, D., Paganelli, E. and Seyler, M. (2014) Percolation of enriched melts during incremental opensystem melting in the spinel field: A REE approach to abyssal peridotites from the Southwest Indian Ridge. Geochimica et Cosmochimica Acta 127, 190-203.

Brunelli, D. and Seyler, M. (2010) Asthenospheric percolation of alkaline melts beneath the St. Paul region (Central Atlantic Ocean). Earth and Planetary Science Letters 289, 393-405.

Brunelli, D., Seyler, M., Cipriani, A., Ottolini, L. and Bonatti, E. (2006) Discontinuous melt extraction and weak refertilization of mantle peridotites at the Vema Lithospheric Section (Mid-Atlantic Ridge). Journal of Petrology 47, 745-771.

Carlson, R.W., Boyet, M. and Horan, M. (2007) Chondrite barium, neodymium, and samarium Isotopic heterogeneity and early earth differentiation. Science 316, 1175-1178.

Cherniak, D. (2010) REE diffusion in olivine. American Mineralogist 95, 362-368.

Dalton, C.A., Langmuir, C.H. and Gale, A. (2014) Geophysical and geochemical evidence for deep temperature variations beneath mid-ocean ridges. Science 344, 80-83.

DeMets, C., Gordon, R.G. and Argus, D.F. (2010) Geologically current plate motions. Geophysical Journal International 181, 1-80.

DePaolo, D.J. (1988) Neodymium Isotope Geochemistry: Neodymium Isotope Geochemistry: An Introduction. Springer Berlin Heidelberg, Berlin, Heidelberg, pp. 3-18.

Feigenson, M.D. and Carr, M.J. (1993) The Source Of Central-American lavas - inferences from geochemical inverse modeling. Contributions to Mineralogy and Petrology 113, 226-235. 
Feigenson, M.D., Hofmann, A.W. and Spera, F.J. (1983) Case studies on the origin of basalt. 2. The transition from tholeiitic of alkalic volcanism on Kohala volcano, Hawaii. Contributions to Mineralogy and Petrology 84, 390-405.

Ghiorso, M.S., Hirschmann, M.M., Reiners, P.W. and Kress, V.C. (2002) The pMELTS: A revision of MELTS for improved calculation of phase relations and major element partitioning related to partial melting of the mantle to $3 \mathrm{GPa}$. Geochemistry, Geophysics, Geosystems 3, 1-35.

Glueckauf, E. (1955) Theory of chromatography. Part 10.-Formulæ for diffusion into spheres and their application to chromatography. Transactions of the Faraday Society 51, 1540-1551.

Grandis, H., Menvielle, M. and Roussignol, M. (1999) Bayesian inversion with Markov chains-I. The magnetotelluric one-dimensional case. Geophysical Journal International 138, 757-768.

Hastings, W.K. (1970) Monte Carlo sampling methods using Markov chains and their applications. Biometrika 57, 97-109.

Hellebrand, E. and Snow, J.E. (2003) Deep melting and sodic metasomatism underneath the highly oblique-spreading Lena Trough (Arctic Ocean). Earth and Planetary Science Letters 216, 283-299.

Hellebrand, E., Snow, J.E., Hoppe, P. and Hofmann, A.W. (2002) Garnet-field melting and late-stage refertilization in 'residual' abyssal peridotites from the Central Indian Ridge. Journal of Petrology 43, 2305-2338.

Hofmann, A. W. (1997) Mantle geochemistry: the message from oceanic volcanism. Nature 385, 219-229.

Hofmann, A.W. and Feigenson, M.D. (1983) Case studies on the origin of basalt. I. Theory and reassessment of Grenada basalts. Contributions to Mineralogy and Petrology 84, 382-389.

Iwamori, H. (1993a) Dynamic disequilibrium melting model with porous flow and diffusion-controlled chemical equilibration. Earth and Planetary Science Letters 114, 301-313.

Iwamori, H. (1993b) A model for disequilibrium mantle melting incorporating melt transport by porous and channel flows. Nature 366, 734-737.

Iwamori, H. (1994) 238U-230Th-226Ra and 235U-231Pa disequilibria produced by mantle melting with porous and channel flows. Earth and Planetary Science Letters 125, 1-16.

Johnson, K.T.M., Dick, H.J.B. and Shimizu, N. (1990) Melting in the oceanic upper mantle: An ion microprobe study of diopsides in abyssal peridotites. Journal of Geophysical Research: Solid Earth 95, 2661-2678.

Jull, M., Kelemen, P.B. and Sims, K. (2002) Consequences of diffuse and channelled porous melt migration on uranium series disequilibria. Geochimica et Cosmochimica Acta 66, 4133-4148.

Katz, R.F. (2008) Magma dynamics with the enthalpy method: benchmark solutions and magmatic focusing at mid-ocean ridges. Journal of Petrology 49, 2099-2121.

Kelemen, P.B., Hirth, G., Shimizu, N., Spiegelman, M. and Dick, H.J.B. (1997) A review of melt migration processes in the adiabatically upwelling mantle beneath oceanic spreading ridges. Philosophical Transactions: Mathematical, Physical and Engineering Sciences 355, 283-318.

Kelley, K.A., Plank, T., Grove, T.L., Stolper, E.M., Newman, S. and Hauri, E. (2006) Mantle melting as a function of water content beneath back-arc basins. Journal of Geophysical Research: Solid Earth 111.

Korenaga, J. and Karato, S.-I. (2008) A new analysis of experimental data on olivine rheology. Journal of Geophysical Research: Solid Earth 113, B02403.

Langmuir, C., Bezos, A., Escrig, S. and Parman, S. (2006) Hydrous mantle melting at ridges and back-arc basins. Geochimica et Cosmochimica Acta 70, A341.

Langmuir, C.H., Bender, J.F., Bence, A.E., Hanson, G.N. and Taylor, S.R. (1977) Petrogenesis of basalts from the FAMOUS area: Mid-Atlantic Ridge. Earth and Planetary Science Letters 36, 133-156. 
Lassiter, J.C., Byerly, B.L., Snow, J.E. and Hellebrand, E. (2014) Constraints from Os-isotope variations on the origin of Lena Trough abyssal peridotites and implications for the composition and evolution of the depleted upper mantle. Earth and Planetary Science Letters 403, 178-187.

Liang, Y. (2003) On the thermo-kinetic consequences of slab melting. Geophysical Research Letters 30, 2270, doi: 10.1029/2003GL018969.

Liang, Y. and Liu, B. (2016) Simple models for disequilibrium fractional melting and batch melting with application to REE fractionation in abyssal peridotites. Geochimica et Cosmochimica Acta 173, 181197.

Liang, Y. and Parmentier, E.M. (2010) A two-porosity double lithology model for partial melting, melt transport and melt-rock reaction in the mantle: mass conservation equations and trace element transport. Journal of Petrology 51, 125-152.

Liang, Y. and Peng, Q. (2010) Non-modal melting in an upwelling mantle column: Steady-state models with applications to REE depletion in abyssal peridotites and the dynamics of melt migration in the mantle. Geochimica et Cosmochimica Acta 74, 321-339.

Liu, J.S. (2008) Monte Carlo Strategies in Scientific Computing. Springer Science \& Business Media.

Lundstrom, C. (2000) Models of U-series disequilibria generation in MORB: the effects of two scales of melt porosity. Physics of the Earth and Planetary Interiors 121, 189-204.

Mallick, S., Dick, H.J.B., Sachi-Kocher, A. and Salters, V.J.M. (2014) Isotope and trace element insights into heterogeneity of subridge mantle. Geochemistry, Geophysics, Geosystems 15, 2438-2453.

McKenzie, D. (1984) The generation and compaction of partially molten rock. Journal of Petrology 25, 713-765.

McKenzie, D. (1985) ${ }^{230} \mathrm{Th}^{238} \mathrm{U}$ disequilibrium and the melting processes beneath ridge axes. Earth and Planetary Science Letters 72, 149-157.

McKenzie, D. and O'Nions, R.K. (1991) Partial melt distributions from inversion of rare earth element concentrations. Journal of Petrology 32, 1021-1091.

McKenzie, D. and O'Nions, R.K. (1995) The source regions of ocean island basalts. Journal of Petrology 36, 133-159.

McKenzie, D. and O'Nions, R.K. (1998) Melt production beneath oceanic islands. Physics of the Earth and Planetary Interiors 107, 143-182.

McKenzie, D., Stracke, A., Blichert-Toft, J., Albarede, F., Gronvold, K. and O'Nions, R.K. (2004) Source enrichment processes responsible for isotopic anomalies in oceanic island basalts. Geochimica Et Cosmochimica Acta 68, 2699-2724.

Metropolis, N., Rosenbluth, A.W., Rosenbluth, M.N., Teller, A.H. and Teller, E. (1953) Equation of state calculations by fast computing machines. The Journal of Chemical Physics 21, 1087-1092.

Minster, J.F. and Allegre, C.J. (1978) Systematic use of trace-elements In igneous processes. III. Inverse problem of batch partial melting in volcanic suites. Contributions to Mineralogy and Petrology 68, $37-52$.

Morgan, J.P. and Forsyth, D.W. (1988) Three-dimensional flow and temperature perturbations due to a transform offset: Effects on oceanic crustal and upper mantle structure. Journal of Geophysical Research: Solid Earth 93, 2955-2966.

Navon, O. and Stolper, E. (1987) Geochemical consequences of melt percolation: The upper mantle as a chromatographic column. The Journal of Geology 95, 285-307.

Niu, Y. (2004) Bulk-rock major and trace element compositions of abyssal peridotites: Implications for mantle melting, melt extraction and post-melting processes beneath mid-ocean ridges. Journal of Petrology 45, 2423-2458. 
Niu, Y. and Hékinian, R. (1997) Spreading-rate dependence of the extent of mantle melting beneath ocean ridges. Nature 385, 326-329.

Niu, Y. and O'Hara, M.J. (2008) Global correlations of ocean ridge basalt chemistry with axial depth: a new perspective. Journal of Petrology 49, 633-664.Ormerod, D.S., Rogers, N.W. and Hawkesworth, C.J. (1991) Melting in the lithospheric mantle - Inverse modeling of alkali-olivine basalts from the Big Pine volcanic field, California. Contributions to Mineralogy and Petrology 108, 305-317.

Ozawa, K. (2001) Mass balance equations for open magmatic systems: Trace element behavior and its application to open system melting in the upper mantle. Journal of Geophysical Research: Solid Earth $106,13407-13434$.

Parker, R.L. (1977) Understanding inverse theory. Annual Review of Earth and Planetary Sciences 5, 35.

Qin, Z. (1992) Disequilibrium partial melting model and its implications for trace element fractionations during mantle melting. Earth and Planetary Science Letters 112, 75-90.

Ribe, N.M. (1985) The deformation and compaction of partial molten zones. Geophysical Journal International 83, 487-501.

Richter, F.M. (1986) Simple models for trace element fractionation during melt segregation. Earth and Planetary Science Letters 77, 333-344.

Richter, F.M. and DePaolo, D.J. (1987) Numerical models for diagenesis and the Neogene Sr isotopic evolution of seawater from DSDP Site 590B. Earth and Planetary Science Letters 83, 27-38.

Robert, C. and Casella, G. (2004) Monte Carlo statistical methods, second edition. Springer Science \& Business Media.

Roland, E., Behn, M.D. and Hirth, G. (2010) Thermal-mechanical behavior of oceanic transform faults: Implications for the spatial distribution of seismicity. Geochemistry, Geophysics, Geosystems 11. doi:10.1029/2010GC003034

Salters, V.J.M. and Dick, H.J.B. (2002) Mineralogy of the mid-ocean-ridge basalt source from neodymium isotopic composition of abyssal peridotites. Nature 418, 68-72.

Sambridge, M. and Mosegaard, K. (2002) Monte Carlo methods in geophysical inverse problems. Reviews of Geophysics 40, 1009.

Shimizu, N. (1998) The geochemistry of olivine-hosted melt inclusions in a FAMOUS basalt ALV519-41. Physics of the Earth and Planetary Interiors 107, 183-201.

Shaw, D.M. (2000) Continuous (dynamic) melting theory revisited. The Canadian Mineralogist 38, 10411063.

Shaw, D. M. (2006) Trace Elements in Magmas: A Theoretical Treatment. Cambridge University Press.

Shu, C.-W. and Osher, S. (1988) Efficient implementation of essentially non-oscillatory shock-capturing schemes. Journal of Computational Physics 77, 439-471.

Smith, P.M. and Asimow, P.D. (2005) Adiabat_1ph: A new public front-end to the MELTS, pMELTS, and pHMELTS models. Geochemistry, Geophysics, Geosystems 6. doi: 10.1029/2004GC000816.

Spiegelman, M. and Kelemen, P.B. (2003) Extreme chemical variability as a consequence of channelized melt transport. Geochemistry, Geophysics, Geosystems 4. doi: 10.1029/2002GC000336.

Sun, C. and Liang, Y. (2014) An assessment of subsolidus re-equilibration on REE distribution among mantle minerals olivine, orthopyroxene, clinopyroxene, and garnet in peridotites. Chemical Geology 372, 80-91.

Tainton, K.M. and McKenzie, D. (1994) The generation of kimberlites, lamproites, and their source rocks. Journal of Petrology 35, 787-817. 
Tarantola, A. (2005) Inverse problem theory and methods for model parameter estimation. Society for Industrial and Applied Mathematics, Philadelphia, PA.

Turcotte, D.L. and Schubert, G. (2002) Geodynamics. Cambridge University Press.

868 Van Orman, J.A., Grove, T.L. and Shimizu, N. (2002) Diffusive fractionation of trace elements during 869 production and transport of melt in Earth's upper mantle. Earth and Planetary Science Letters 198, 93-112.

Walter, M.J. (1998) Melting of garnet peridotite and the origin of komatiite and depleted lithosphere. Journal of Petrology 39, 29-60.

873 Warren, J.M. (2016) Global variations in abyssal peridotite compositions. Lithos 248-251, 193-219.

874 Watson, S. (1993) Rare earth element inversions and percolation models for Hawaii. Journal of Petrology $87534,763-783$.

876 Watson, S. and McKenzie, D. (1991) Melt generation by plumes - A study of Hawaiian volcanism. 877 Journal of Petrology 32, 501-537.

878 White, R.S., McKenzie, D. and O'Nions, R.K. (1992) Oceanic crustal thickness from seismic 879 measurements and rare earth element inversions. Journal of Geophysical Research: Solid Earth 97, $880 \quad 19683-19715$.

881 Workman, R.K. and Hart, S.R. (2005) Major and trace element composition of the depleted MORB

883 Zou, H. (1998) Trace element fractionation during modal and nonmodal dynamic melting and open884 system melting: a mathematical treatment. Geochimica et Cosmochimica Acta 62, 1937-1945.

885 Zou, H. (2007). Quantitative Geochemistry. London, UK: Imperial college press. 


\section{Figure Captions}

887 Figure 1. Comparison between observed (circles) and model derived (lines) REE + Y patterns in 888 residual clinopyroxene in spinel lherzolite. The observed data are from an abyssal peridotite from the Central Indian Ridge (Hellebrand et al., 2002, their sample ANTP126-2). Individual

890 lines are calculated using the disequilibrium fractional melting model (Eq. 6) through 891 MCMC simulations. Concentrations in clinopyroxene are normalized by CI chondrite $892 \quad$ (Anders and Grevesse, 1989).

893 Figure 2. Histograms displaying MCMC simulation results of sample ANTP126-2 for the degree 894 of melting $\left(F\right.$, panel a) and the disequilibrium parameter for La in clinopyroxene $\left(\varepsilon_{L a}\right.$, panel b) 895 obtained using the disequilibrium fractional melting model (Eq. 6). Black solid line in each 896 panel marks the most probable model. Black dashed lines are the upper and lower $\sigma$ about the 897 most probable model. Red curves correspond to the normal distribution based on nonlinear $898 \quad$ least squares inversion.

899 Figure 3. Plot of accepted model parameters for sample ANTP126-2 in $F-\varepsilon_{L a}$ plane. Red error 900 bars correspond to the most probable model with upper/lower $\sigma$. Blue error bars correspond 901 to mean $\pm \sigma$. Also shown are results from nonlinear least squares inversion (ellipses). The 902 larger ellipse corresponds to $95 \%$ confidence level, while the smaller ellipse corresponds to $90368.2 \%$ confidence level. The $68.2 \%$ confidence eclipse underestimates the uncertainties of $F$ 904 and $\varepsilon$ for La in clinopyroxene .

905 Figure 4. Comparison of melting parameters derived from MCMC simulations and nonlinear 906 least squares inversions of REE $+\mathrm{Y}$ in residual clinopyroxenes in abyssal peridotites from 907 the Central Indian Ridge (data from Hellebrand et al., 2002). (a) Degree of melting $(F)$. (b) 

$\varepsilon_{L a}$, disequilibrium parameter for La in clinopyroxene. Subscripts 'MP' and 'LS' refer to the most probable model parameter from MCMC simulations and nonlinear least squares method.

$910 \quad$ See text for discussion.

911 Figure 5. Comparison between observed (circles) and model derived REE + Y patterns in 912 clinopyroxene in abyssal peridotites. Three samples from the Central Indian Ridge 913 (Hellebrand et al., 2002) are shown as examples of disequilibrium fractional melting (a), 914 disequilibrium dynamic melting (b), and equilibrium dynamic melting (c). Individual curves 915 are calculated using the disequilibrium dynamic melting model (Eqs. 9-11) through MCMC 916 simulations. Parameters for the most probable model are listed in each panel. See text for 917 discussion.

918 Figure 6. Histograms displaying MCMC simulation results of sample ANTP126-2 for the degree 919 of melting $\left(F\right.$, panel a), the disequilibrium parameter for La in clinopyroxene $\left(\varepsilon_{L a}\right.$, panel b), 920 and the mass flux ratio or fraction of melt retained ( $\alpha$, panel c) obtained using the 921 disequilibrium dynamic melting model (Eqs. 9-11). Solid line in each panel represents the 922 most probable model. Dashed lines mark uncertainty interval about the most probable model. 923 Notice the most probable model parameter may lie on the boundary of uncertainty interval.

924 Figure 7. Plots of accepted model parameters for three samples in $F-\varepsilon_{L a}$ plane (a, d, g), $\varepsilon_{L a}-\alpha$ 925 plane $(\mathrm{b}, \mathrm{e}, \mathrm{h})$, and $F-\varepsilon_{L a}-\alpha$ space $(\mathrm{c}, \mathrm{f}, \mathrm{i})$. Model parameters are derived from MCMC 926 simulations using the disequilibrium dynamic melting model (Eqs. 9-11). Red error bars 927 correspond to the most probable model with upper/lower $\sigma$. Blue error bars correspond to the 928 symmetric format of mean $\pm \sigma$. The gold shade regions in the 3D space mark the ranges of $10 \%$ 929 best models. 
930 Figure 8. Comparison of the most probable parameters ( $F$ and $\varepsilon_{L a}$ ) derived from MCMC 931 simulations using the disequilibrium perfect fractional melting model (Eq. 6) and the 932 disequilibrium dynamic melting model (Eqs. 9-11) for samples from the Central Indian 933 Ridge in the two case studies discussed in Section 3. Results for a given sample from the two 934 case studies are connected by a dashed line. The disequilibrium fractional melting model in 935 case one overestimates $\varepsilon$ when $F$ is smaller than $13 \%$.

936 Figure 9. Plots of inverted $F$ and the disequilibrium parameter $\varepsilon_{L a}$ for samples from selected 937 ridges (see Table 2 for data source). The arrows and magenta squares in (a) suggest models 938 closer to the main trend can explain these two samples. (The REE pattern derived from the 939 on-trend model can be found in supplementary Figure S2.) Samples from SWIR and CIR 940 show robust positive trends. $\mathrm{N}$ is the number of samples from a given ridge system.

941 Figure 10. Variations of the calculated disequilibrium parameter $\varepsilon_{L a}$ as a function of $F$ along 942 three adiabat melting paths (solid curves). Dashed lines are arithmetic average of $\varepsilon_{L a}$ from the 943 onset of melting to $F$. In general, $\varepsilon_{L a}$ increases with initial grain size (d) and decreases with 944 potential temperature $\left(T_{p}\right)$. To facilitate comparison, we renormalize $\varepsilon_{L a}$ from different ridges 945 (symbols) to a reference spreading rate of $V_{0}=30 \mathrm{~mm} / \mathrm{yr}$. See text for discussion.

946 Figure 11. Plots of inverted degree of melting $F$ (panel a) and normalized disequilibrium 947 parameters $\varepsilon_{L a}\left(V_{O} / V_{s p}\right) / F\left(\right.$ panel b) as a function of spreading rate. $\varepsilon_{L a}$ increases with initial 948 grain size $(d)$ and decreases with potential temperature ( $T_{p}$, marked by arrows in b). The 949 magenta bar represents the average over the interval of spreading rate.

950 Figure 12. Variations of $\varepsilon_{L a}$ in clinopyroxene along the Vema Lithospheric Section at Mid951 Atlantic Ridge (trace element data from Brunelli et al., 2006). 
952 Figure 13. The grain size distribution of samples from VLS (a, c, e) and Marie Celeste transform 953 fault at CIR (b, d, f) assuming potential temperature of $1280^{\circ} \mathrm{C}, 1310^{\circ} \mathrm{C}$, or $1340^{\circ} \mathrm{C}$. Above 954 each plot is the average grain size $( \pm \sigma)$ for the three cases obtained by bootstrap resampling.

955 Figure 14. Diagram showing the lack of correlation between $\varepsilon_{L a}$ in clinopyroxene and $956{ }^{143} \mathrm{Nd} /{ }^{144} \mathrm{Nd}$ in clinopyroxene for 19 samples from the Mid-Atlantic ridge (VLS and KSP) 957 and the Southwest Indian Ridge (SWIR). 
Table 1. List of key symbols.

\begin{tabular}{|c|c|}
\hline Symbol & Description \\
\hline $\mathbf{C}, C_{\mathrm{i}}$ & $\mathbf{C}$ is an array of observed multiple trace element concentrations, $C_{i}$ \\
\hline$C_{\mathrm{f}}$ & Concentration of a trace element in the instantaneous melt \\
\hline$C_{\mathrm{s}}^{0}$ & Concentration of the bulk solid at the onset of melting \\
\hline$d$ & Mineral grain size \\
\hline$d_{0}$ & Reference grain size, $1.5 \mathrm{~mm}$ \\
\hline$D$ & Diffusivity of the element of interest in the mineral \\
\hline$D_{L a}, D_{R E E}$ & Diffusivity of La or REE in the mineral \\
\hline$F$ & Degree of melting experienced by the bulk solid \\
\hline$F_{L S} \pm \sigma_{L S}$ & $\begin{array}{l}\text { The estimate of } F \text { and uncertainty obtained using the nonlinear least squares } \\
\text { method }\end{array}$ \\
\hline$F_{M P}^{+\sigma_{+}}$ & The most probable estimate of $F_{M P}$ and asymmetric uncertainties $\sigma_{+}$and $\sigma_{-}$ \\
\hline$F_{\text {mean }} \pm \sigma$ & The average and standard deviation of all accepted $F$ from MCMC simulations \\
\hline$f_{p}$ & Degree of melting at the onset of dynamic melting, defined in Eq. 15 \\
\hline$k, k_{c p x}$ & Bulk solid-melt or cpx-melt partition coefficient \\
\hline$k_{0}$ & Bulk solid-melt partition coefficient at the onset of melting \\
\hline$k_{p}$ & Bulk solid-melt partition coefficient for the melting reaction \\
\hline$L(\mathbf{C} \mid \mathbf{m})$ & Likelihood of observing $\mathbf{C}$ given the model, $\mathbf{m}$. Defined in Eq. 3 \\
\hline $\mathbf{m}$ & A vector of model parameters \\
\hline$p(\mathbf{m} \mid \mathbf{C})$ & Posterior probability of a model, $\mathbf{m}$, given observation $\mathbf{C}$, defined in Eq. 1 \\
\hline$R$ & The mineral-melt exchange rate constant, defined in Eq. 7 \\
\hline$T_{p}$ & Potential temperature \\
\hline$V_{f}, V_{s}$ & Velocity of the melt or the solid \\
\hline$V_{s p}$ & Spreading rate \\
\hline$V_{0}$ & Reference spreading rate, $30 \mathrm{~mm} / \mathrm{yr}$ \\
\hline$Z$ & Vertical coordinate, measured from the base of the melting column \\
\hline$\alpha$ & The ratio between the melt and solid mass or mass flux ratio, Eq. 11 \\
\hline$\theta(\mathbf{m})$ & The data-independent prior probability of the model, $\mathbf{m}$ \\
\hline$\varepsilon$ & Element specific disequilibrium parameter, Eq. 5 and Eq. 16 \\
\hline$\varepsilon_{L a}, \varepsilon_{R E E}$ & Disequilibrium parameter for La or REE \\
\hline$\varepsilon_{T p}^{0}$ & $\varepsilon$ averaged along a melting path (Tp) with reference grain size and spreading rate \\
\hline$\Phi_{f}$ & Porosity \\
\hline$\Gamma$ & Melting rate of the bulk solid \\
\hline$\rho_{f}, \rho_{s}$ & Density of the melt or the solid \\
\hline$\chi^{2}(\mathbf{C}, \mathbf{m})$ & Chi-square of observation $\mathbf{C}$ given the model, $\mathbf{m}$ \\
\hline
\end{tabular}


Table 2. List of sample locations and sources

\begin{tabular}{|l|c|l|}
\hline Sample location & $\begin{array}{l}\text { Number } \\
\text { of samples }\end{array}$ & Data sources \\
\hline $\begin{array}{l}\text { Southwest Indian Ridge } \\
\text { (SWIR) }\end{array}$ & 35 & $\begin{array}{l}\text { Salters and Dick (2002); Warren (2007); Seyler } \\
\text { et al. (2011); Mallick et al. (2014) }\end{array}$ \\
\hline $\begin{array}{l}\text { Lena Trough (LT) at Arctic } \\
\text { Ridge }\end{array}$ & 25 & $\begin{array}{l}\text { Hellebrand and Snow (2003); Lassiter et al. } \\
(2014)\end{array}$ \\
\hline $\begin{array}{l}\text { American-Antarctic Ridge } \\
\text { (AAR) }\end{array}$ & 9 & Johnson et al. (1990) \\
\hline $\begin{array}{l}\text { Vema Lithospheric Section } \\
\text { (VLS) at Mid-Atlantic Ridge }\end{array}$ & 35 & Brunelli et al. (2006) \\
\hline $\begin{array}{l}\text { Kane FZ \& St. Paul FZ } \\
\text { (KSP) at Mid-Atlantic Ridge }\end{array}$ & 9 & Brunelli and Seyler (2010); Mallick et al. (2014) \\
\hline Central Indian Ridge (CIR) & 22 & Hellebrand et al. (2002) \\
\hline
\end{tabular}


Figure 2

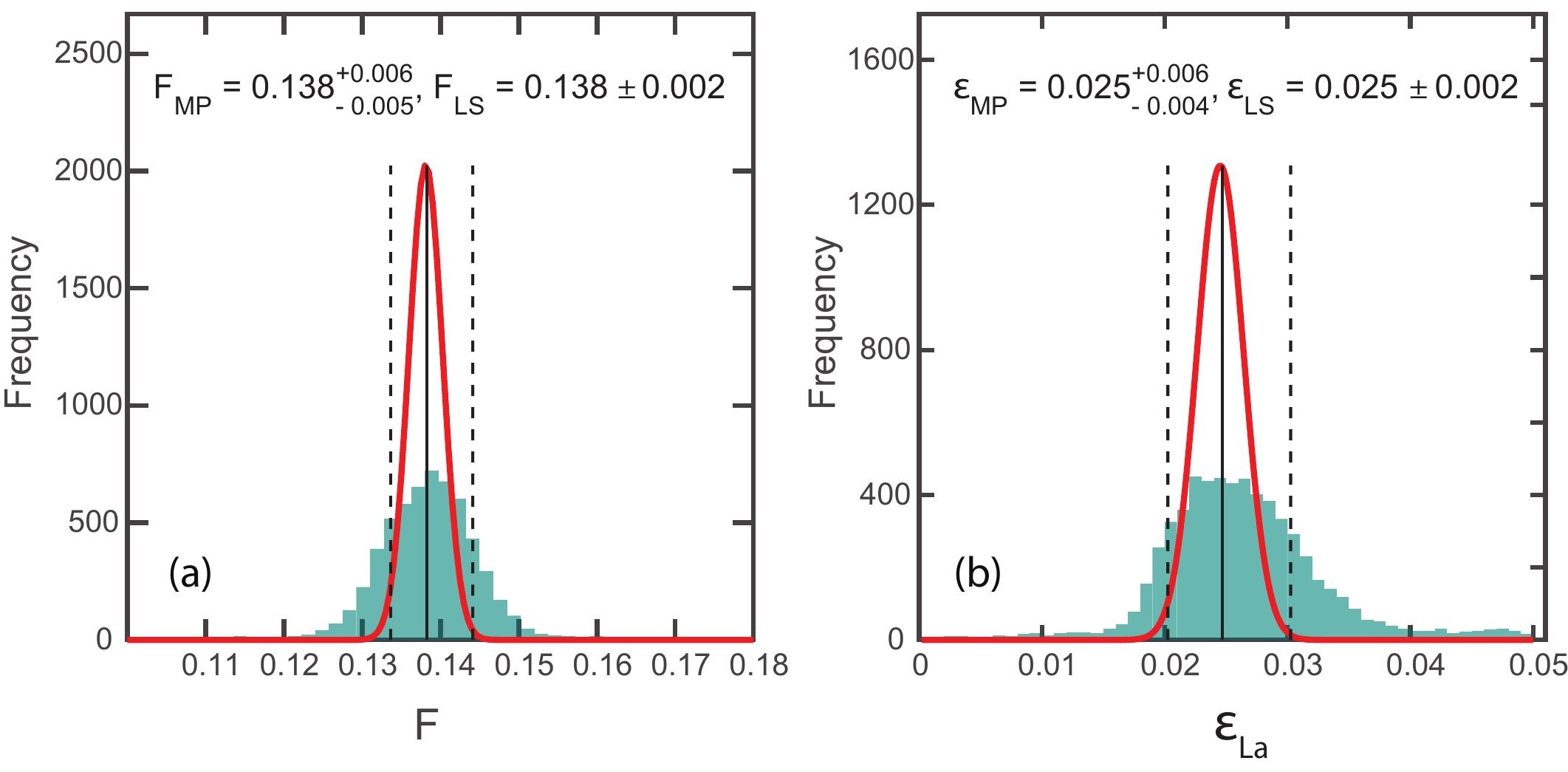




$$
\begin{gathered}
\mathrm{F}_{\mathrm{MP}}=0.138_{-0.005}^{+0.006}, \quad \varepsilon_{\mathrm{MP}}=0.025_{-0.004}^{+0.006} \\
\mathrm{~F}=0.135 \pm 0.018, \quad \varepsilon_{\mathrm{La}}=0.026 \pm 0.007 \\
95.0 \% \text { and } 68.2 \% \text { confidence ellipses from LS }
\end{gathered}
$$

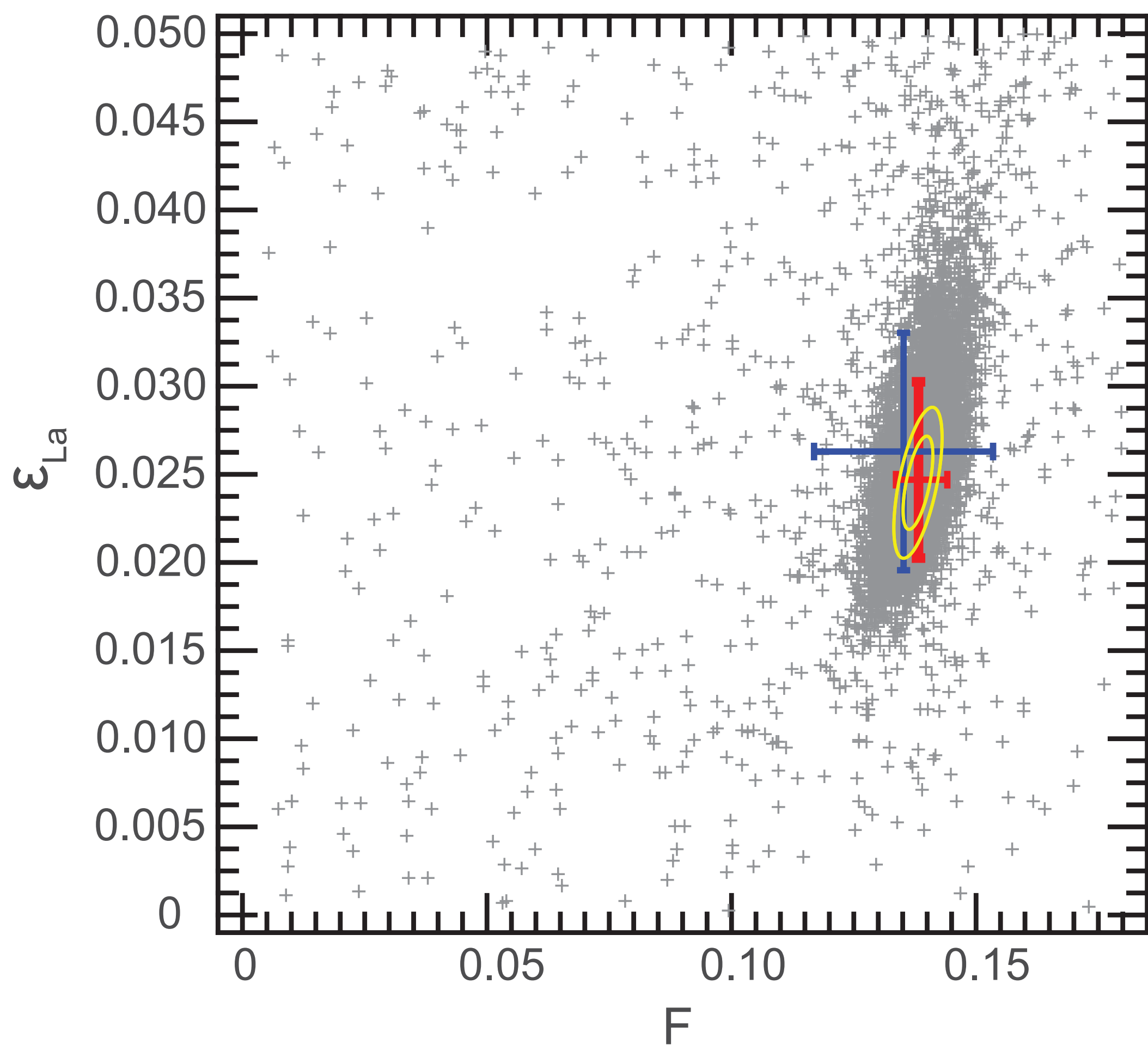



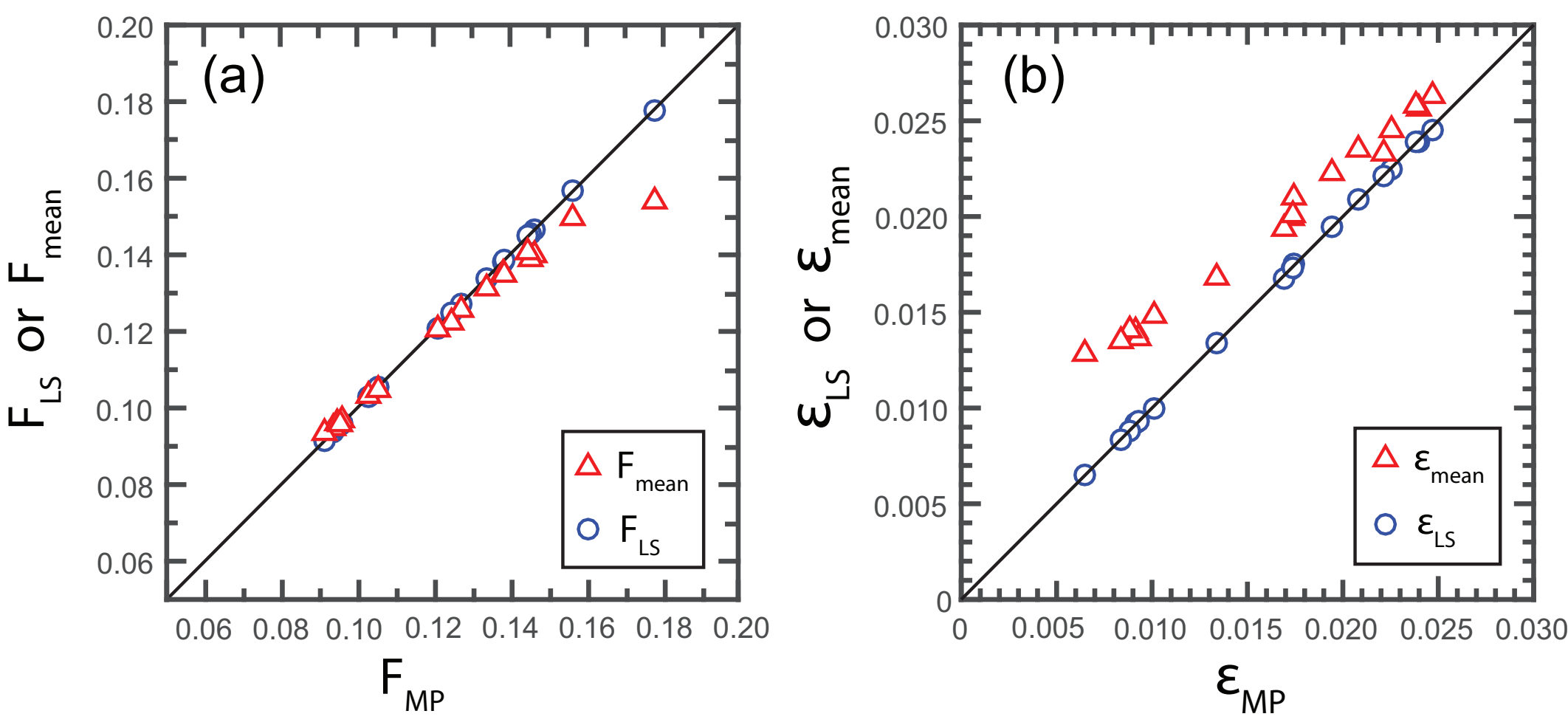

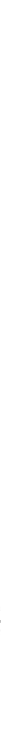

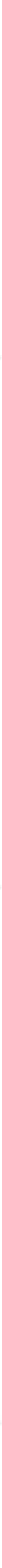


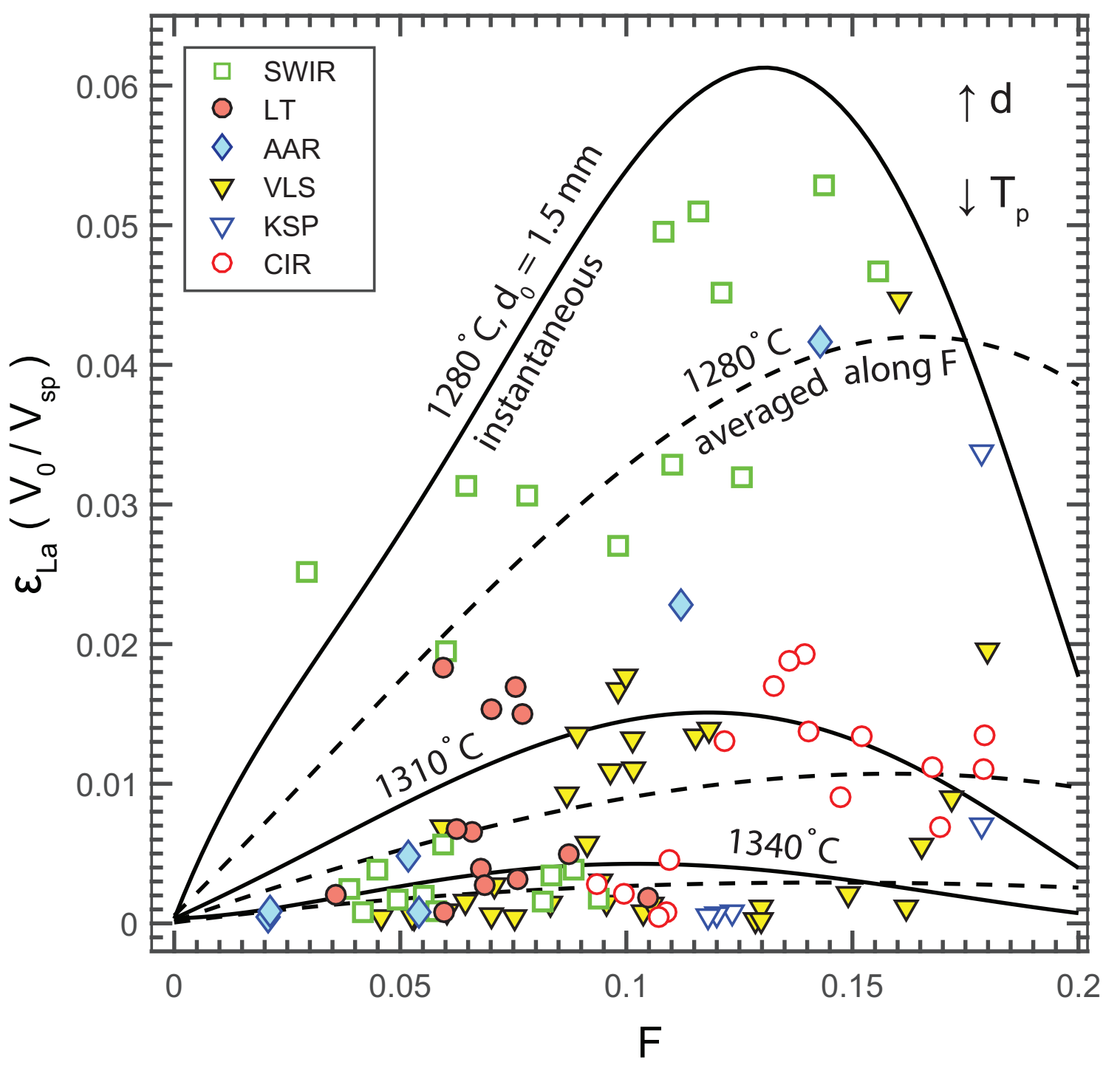



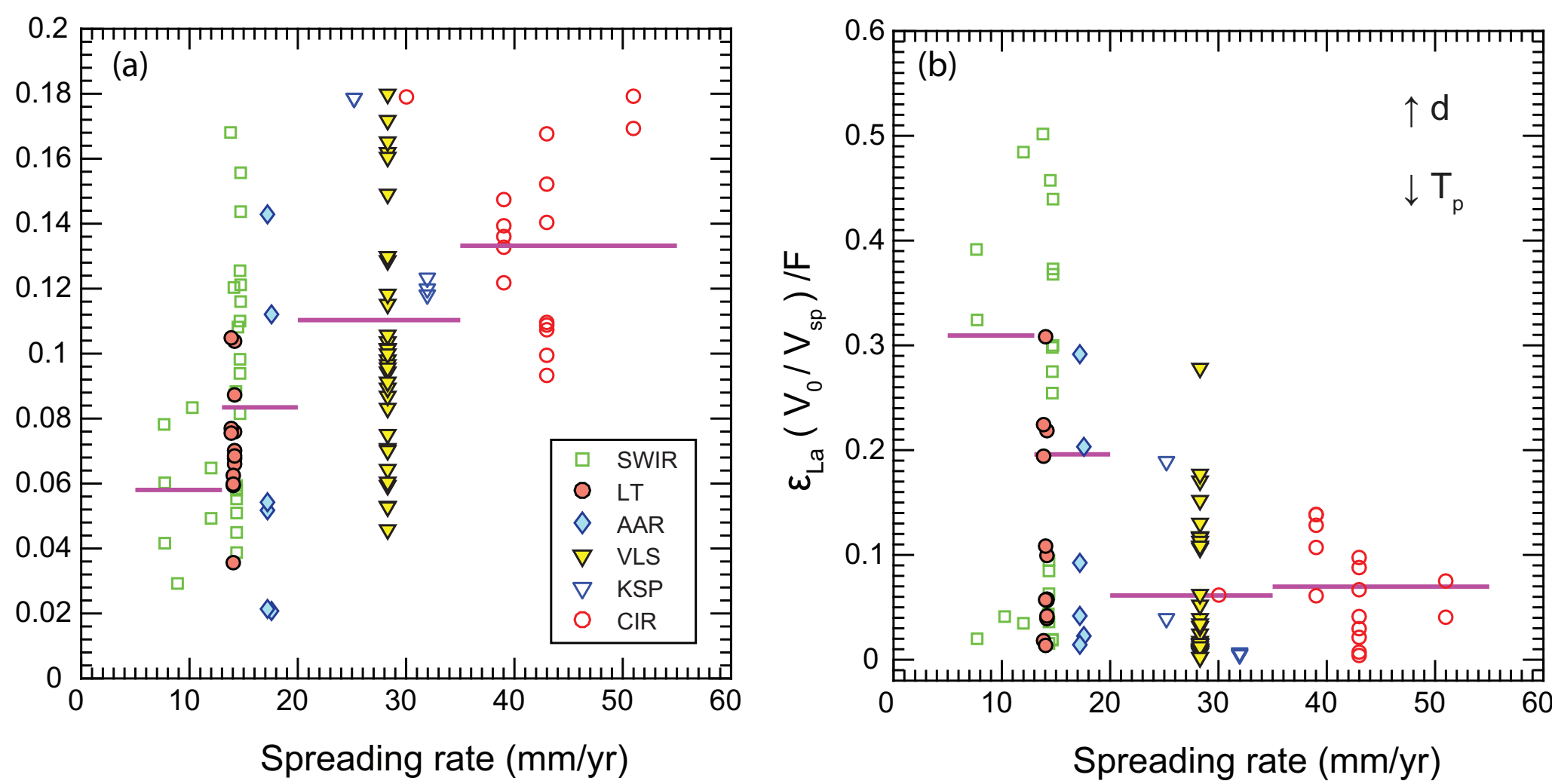


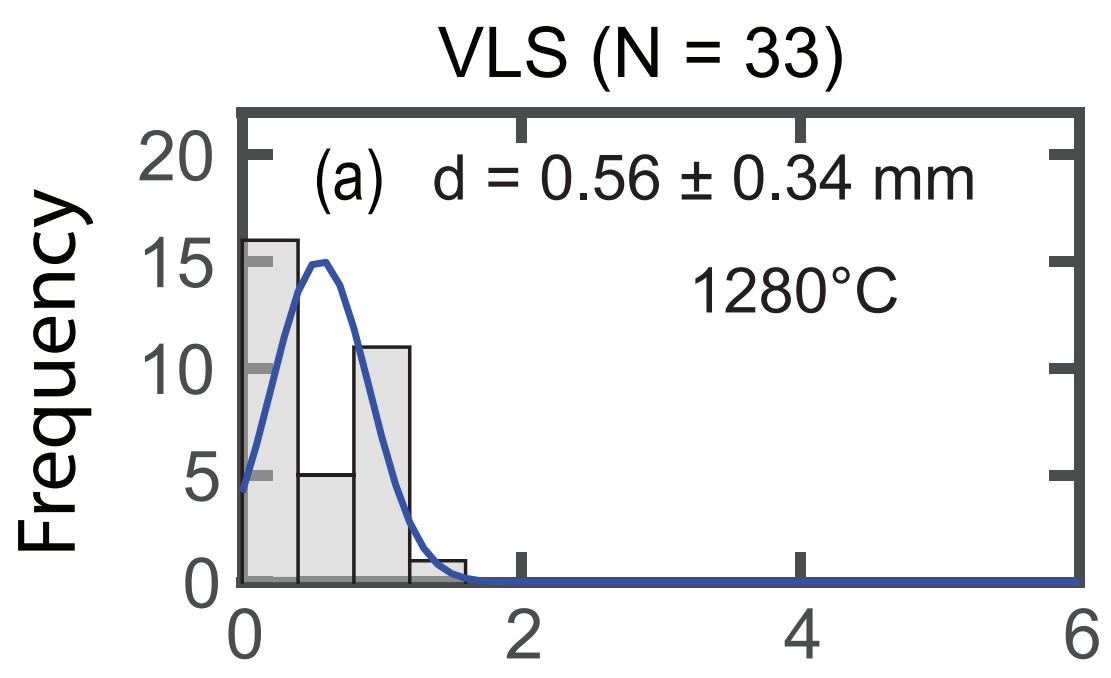

Marie Celests $(\mathrm{N}=9)$
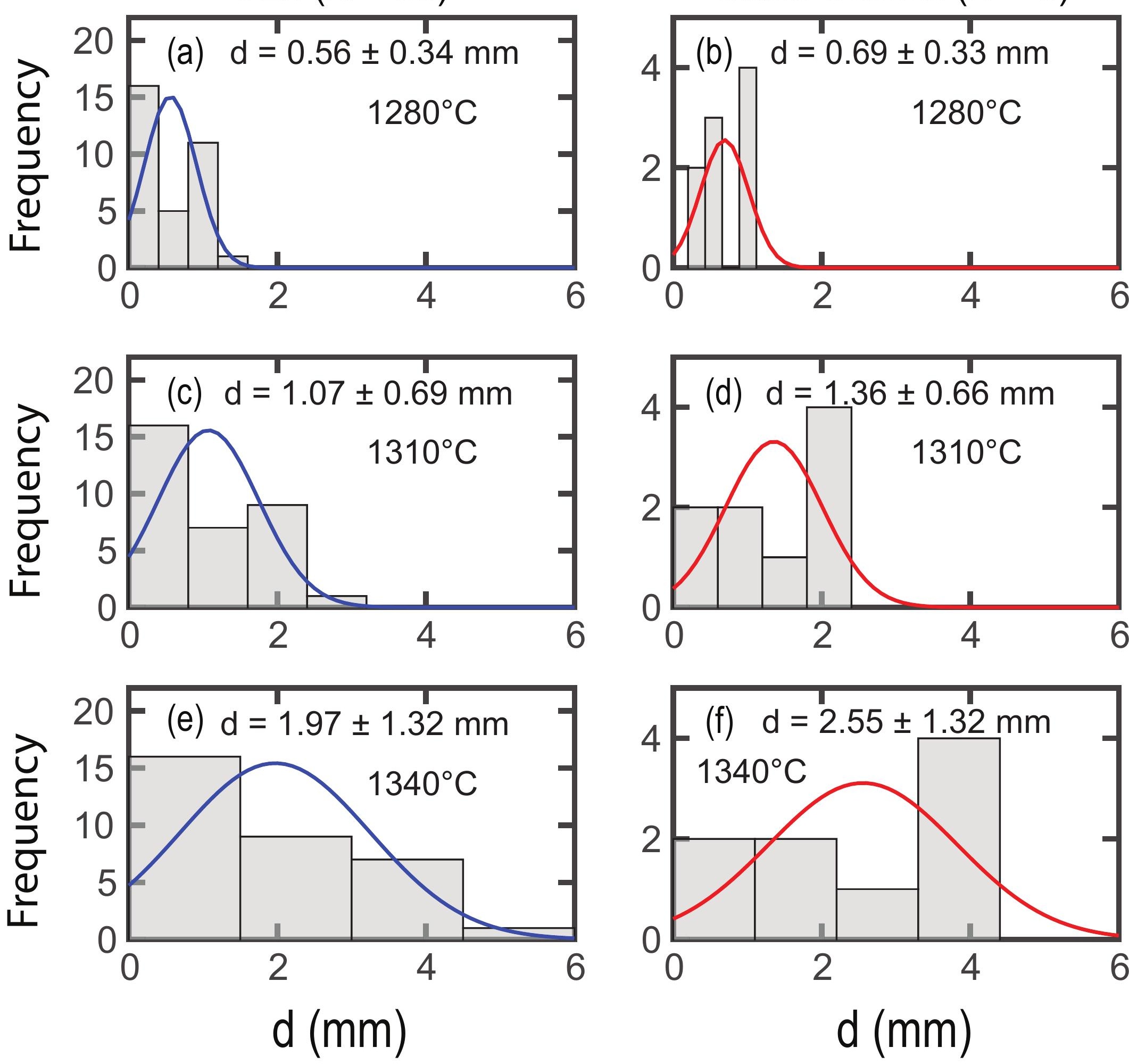


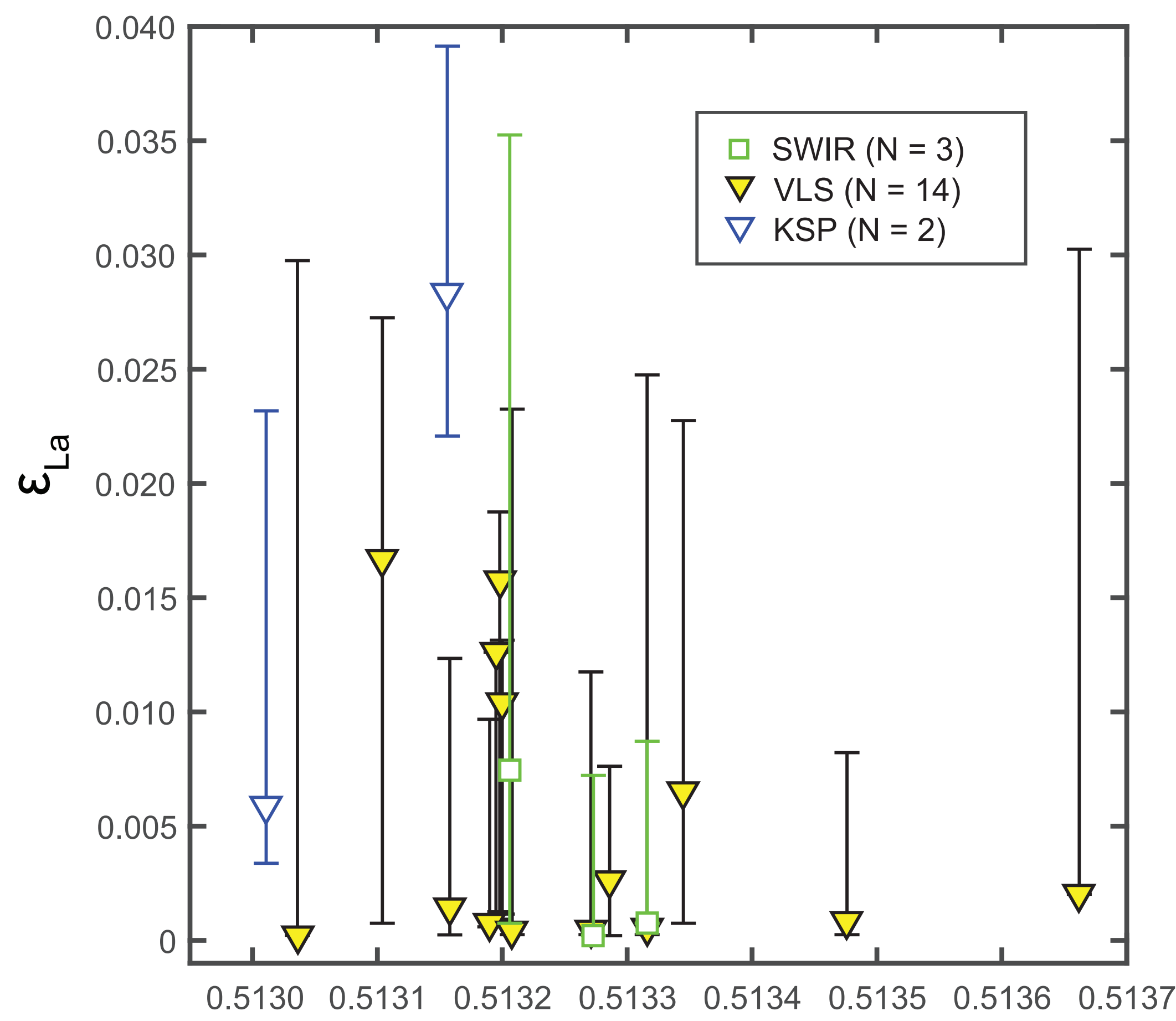

